\title{
Multiple Regioselective Functionalizations of Quinolines via Magnesiations
}

\author{
Nadège Boudet, Jennifer R. Lachs and Paul Knochel* \\ Department Chemie und Biochemie, Ludwig-Maximilians-Universität, \\ Butenandtstrasse 5-13, 81377, München (Germany). \\ Paul.Knochel@cup.uni-muenchen.de
}

\section{Supporting information}

Experimental procedures, analytical and spectroscopy data for starting materials and final products (42 pages). 


\section{General conditions}

Unless otherwise indicated, all reactions were carried out with magnetic stirring and, if air or moisture sensitive, in flame-dried glassware under argon. Syringes used to transfer reagents and solvent were purged with argon prior to use. Reactions were monitored by gas chromatography (GC and GC-MS) or thin layer chromatography (TLC).

i-PrMgCl-LiCl (4): This reagent was directly used from commercial sources such as Chemetall GmbH.

\section{Preparation of the reagent $\mathrm{MesMgBr} \cdot \mathrm{LiCl}(5)$ :}

Magnesium turnings $(110 \mathrm{mmol})$ and anhydrous $\mathrm{LiCl}(100 \mathrm{mmol})$ were placed in an Ar-flushed flask and THF $(25 \mathrm{~mL})$ was added. A solution of mesitylbromide $(100 \mathrm{mmol})$ in THF $(25 \mathrm{~mL})$ was slowly added at $\mathrm{rt}$. The reaction starts within a few minutes. After addition, the reaction mixture was stirred for $12 \mathrm{~h}$ at $\mathrm{rt}$. The grey solution of $\mathrm{MesMgBr} \cdot \mathrm{LiCl}$ was cannulated to another flask under Ar and removed in this way from excess of magnesium. A yield of ca. $95-98 \%$ of $\mathrm{MesMgBr} \cdot \mathrm{LiCl}$ is obtained.

\section{Preparation of the reagent $\mathrm{Mes}_{2} \mathrm{Mg} \cdot 2 \mathrm{LiBr}(6)$ :}

A solution of $t$-BuLi in hexane $(195 \mathrm{mmol}, 1.70 \mathrm{M})$ was added dropwise at $-78{ }^{\circ} \mathrm{C}$ to a solution of mesitylbromide $(100 \mathrm{mmol})$ in $\mathrm{Et}_{2} \mathrm{O}(25 \mathrm{~mL})$ for $15 \mathrm{~min}$. The resulting mixture was first warmed to $-20^{\circ} \mathrm{C}$, and stirred for $1 \mathrm{~h}$, and then warmed to rt. The solvents were evaporated under vacuum for $1 \mathrm{~h}$. To the obtained lithium salt, a solution of $\mathrm{MesMgBr}^{1}$ in THF $(105 \mathrm{mmol}, 0.65 \mathrm{M})$ was added at $-50{ }^{\circ} \mathrm{C}$ and stirred for $1 \mathrm{~h}$. Thereafter, the mixture is allowed to warm to $\mathrm{rt}$ and stirred for $12 \mathrm{~h}$. A clear solution of $\mathrm{Mes}_{2} \mathrm{Mg} \cdot \mathrm{LiBr}$ is obtained and the concentration $(0.61 \mathrm{M}$ of $[\mathrm{Mg}]$ in THF) was checked by titration of iodine ( $1 \mathrm{mmol})$.

Preparation of the reagent TMPMg$\cdot \mathrm{LiCl}^{2}$ (7):

A dry and nitrogen-flushed 250-mL-Schlenk-flask, equipped with a magnetic stirrer and a septum, was charged with freshly titrated $i-\mathrm{PrMgCl} \cdot \mathrm{LiCl}(100 \mathrm{~mL}, 1.2 \mathrm{M}$ in THF, $120 \mathrm{mmol})$. 2,2,6,6-Tetramethylpiperidine (TMPH) (19.8 g, $126 \mathrm{mmol}, 1.05$ equiv) was added dropwise at rt. The reaction mixture was stirred at $\mathrm{rt}$ until gas evolution was completed (ca. $24 \mathrm{~h}$ ). The concentration of the solution of $\mathrm{TMPMgCl} \cdot \mathrm{LiCl}$ was titrated by using benzoic acid in dry THF and 4-(phenylazo)diphenylamine (colour changes from yellow to purple) as an indicator.

Preparation of the reagent $\mathbf{T M P}_{2} \mathbf{M g} \cdot 2 \mathrm{LiCl}(8)$ : according to the known procedure. ${ }^{3}$

Preparation of the reagent $\mathrm{CuCN} \cdot 2 \mathrm{LiCl}$ in THF: according to the known procedure. ${ }^{4}$

\section{General procedure for the $\mathrm{Br} / \mathrm{Mg}$ exchange reaction using $\mathrm{i}-\mathrm{PrMgCl} \cdot \mathrm{LiCl}$ (4) or MesMgBr·LiCl (5) as magnesiation reagent (GP 1):}

A dry and argon flushed flask, equipped with a magnetic stirring bar and a septum, was charged with the neat quinoline derivative (1 equiv) dissolved in dry THF (1.0 M solution). The magnesiation reagent 4 or 5 (1.1 equiv) was added slowly, dropwise, at appropriate temperature (as stated in the experiment). The reaction mixture was stirred at the same temperature, and the completion of the $\mathrm{Br} / \mathrm{Mg}$ exchange was checked by GC-analysis using decane as internal standard or by TLC. The freshly prepared magnesium reagent was cooled

\footnotetext{
${ }^{1}$ This reagent was directly used from commercial sources such as Aldrich.

${ }^{2}$ Krasovskiy, A.; Krasovskaya, V.; Knochel, P. Angew. Chem. Int. Ed. 2006, 45, 2958

${ }^{3}$ Clososki, G. C.; Rohbogner, C. J. Angew. Chem. Int. Ed. 2007, 46, 7681.

${ }^{4}$ Knochel, P.; Yeh, M. C. P.; Berk, S. C.; Talbert, J. J. Org. Chem. 1988, 53, 2390.
} 
to the corresponding temperature or used at room temperature and the corresponding electrophile (1.2 or 1.3 equiv) or its solution in THF was added. The mixture was stirred for a time depending on the reactivity of the electrophile. The consumption of the magnesium reagent was checked by GC-analysis, using decane as internal standard. After the reaction was completed, sat. $\mathrm{NH}_{4} \mathrm{Cl}$ solution was added and the mixture was extracted three times with $\mathrm{Et}_{2} \mathrm{O}$ or EtOAc. The solvent was evaporated and the product was purified by flashchromatography $\left(\mathrm{SiO}_{2}\right)$.

\section{General procedure for the deprotonation using TMPMg$\cdot \mathrm{LiCl}(7)$ or $(\mathrm{TMP})_{2} \mathrm{Mg} \cdot 2 \mathrm{LiCl}(8)$ (GP 2):}

A dry and argon flushed flask, equipped with a magnetic stirring bar and a septum, was charged with the neat quinoline derivative (1 equiv) dissolved in dry THF (1.0 M solution) and 1.1 equivalents of $\mathbf{7}$ or $\mathbf{8}$ were added dropwise at the given temperature. The reaction mixture was stirred at the same temperature, and the completion of the deprotonation was checked by GC-analysis of reaction aliquots quenched with iodine using decane as internal standard. The freshly prepared magnesium reagent was cooled to the corresponding temperature or used at room temperature and the corresponding electrophile (1.2 equiv) or its solution in THF was added. The mixture was stirred for a time depending on the reactivity of the electrophile. The consumption of the magnesium reagent was checked by GC-analysis, using decane as internal standard. After the reaction was completed, sat. $\mathrm{NH}_{4} \mathrm{Cl}$ solution was added and the mixture was extracted three times with $\mathrm{Et}_{2} \mathrm{O}$ or EtOAc. The solvent was evaporated and the product was purified by flash-chromatography $\left(\mathrm{SiO}_{2}\right)$.

\section{General procedure for the reaction with acyl chlorides (GP 3):}

According to GP1 or GP2, the freshly prepared magnesium reagent was cooled to $-40{ }^{\circ} \mathrm{C}$, and $\mathrm{CuCN} \cdot 2 \mathrm{LiCl}$ ( 1 equiv, $1.00 \mathrm{M}$ in THF) was added and stirred for $30 \mathrm{~min}$. Thereafter, acyl chloride ( 1.5 equiv) was added at $-40{ }^{\circ} \mathrm{C}$, and the reaction mixture was warmed to $\mathrm{rt}$ and stirred for the appropriate time. The reaction mixture was quenched with sat. aq. $\mathrm{NH}_{4} \mathrm{Cl}$ solution or $\mathrm{NH}_{4} \mathrm{OH}$ (2M aq.) extracted with $\mathrm{Et}_{2} \mathrm{O}$ or EtOAc and dried over anhydrous $\mathrm{Na}_{2} \mathrm{SO}_{4}$. After filtration, the solvent was evaporated in vacuo. Purification by flashchromatography furnished the desired product.

\section{Synthesis of 2,3-dibromoquinoline (9a)}

Prepared according to GP 2 from 3-bromoquinoline (14) (6 mmol, $1.24 \mathrm{~g})$, TMPMgCl $\mathrm{LiCl}$ (7) [reaction condition: $-20^{\circ} \mathrm{C}$ for $2 \mathrm{~h}$ ], and 1,2-dibromo-1,1,2,2-tetrachloroethane $(6.6 \mathrm{mmol}$, $2.14 \mathrm{~g}$, in $6 \mathrm{~mL}$ of THF) [reaction condition: $-20^{\circ} \mathrm{C}$ to $\mathrm{rt}$ for $12 \mathrm{~h}$ ]. Purification by flashchromatography $\left(\mathrm{SiO}_{2}\right.$, pentane/ether - 19/1) yielded 2,3-dibromoquinoline (9a, $\left.1.11 \mathrm{~g}, 65 \%\right)$ as a white solid.

mp.: $110.2-112.0^{\circ} \mathrm{C}$.

${ }^{1} \mathbf{H}-\mathbf{N M R}\left(\mathbf{C D C l}_{3}, 300 \mathrm{MHz}\right): \delta(\mathrm{ppm})=8.36(\mathrm{~s}, 1 \mathrm{H}), 8.01\left(\mathrm{~d},{ }^{3} \mathrm{~J}=8.8 \mathrm{~Hz}, 1 \mathrm{H}\right), 7.76-7.71$ (m, $2 \mathrm{H}), 7.58\left(\mathrm{t},{ }^{3} J=7.5 \mathrm{~Hz}, 1 \mathrm{H}\right)$.

${ }^{13}$ C-NMR (CDCl 3 , 75 MHz): $\delta(\mathrm{ppm})=146.7,142.8,140.4,130.8,130.8,128.6,128.0$, 126.7, 119.7.

IR (ATR): $v\left(\mathrm{~cm}^{-1}\right)=3046(\mathrm{~s}), 1614(\mathrm{~m}), 1572(\mathrm{~m}), 1558(\mathrm{~m}), 1546(\mathrm{~s}), 1484(\mathrm{~s}), 1360(\mathrm{~s})$, 1318 (s), 1292 (m), 1200 (m), 1150 (m), 1132 (m), 1110 (vs), 950 (s), 916 (s), 772 (s), 746 (vs), $662(\mathrm{~m}), 626(\mathrm{~m})$.

MS (EI, 70 eV): $m / z(\%)=288(31)\left[\mathrm{M}^{+},{ }^{81} \mathrm{Br}\right], 286(100)\left[\mathrm{M}^{+},{ }^{81} \mathrm{Br},{ }^{79} \mathrm{Br}\right], 284$ (37) $\left[\mathrm{M}^{+}\right.$, ${ }^{79} \mathrm{Br}$ ], 207 (68), 205 (56), 127 (73), 74 (11).

HR-MS: $\left(\mathrm{C}_{9} \mathrm{H}_{5}{ }^{79} \mathrm{Br}_{2} \mathrm{~N}\right) \quad$ calculated $284.8789 \quad$ found 284.8765 


\section{Synthesis of 2,4-dibromoquinoline ${ }^{5}$ (9b)}

A mixture of commercially available quinoline-2,4-diol (30 mmol, $4.835 \mathrm{~g})$ and phosphorus oxybromide (120 mmol, $34 \mathrm{~g})$ was refluxed for $5 \mathrm{~h}$ in dry toluene $(300 \mathrm{~mL})$. After cooling in an icebath, the reaction mixture was hydrolyzed carefully by addition of ice $(200 \mathrm{~mL})$ and neutralized using a $6 \mathrm{~N}$ solution of sodium hydroxide. The insoluble product was collected by filtration, washed with water $(3 \times 100 \mathrm{~mL})$ and dried under vacuum. 2,4-dibromoquinoline (9b) was obtained as a pale yellow solid $(6.4 \mathrm{~g}, 75 \%)$.

mp.: $93.8-95{ }^{\circ} \mathrm{C}$.

${ }^{1}$ H-NMR (DMSO-d 6 , 300 MHz): $\delta(\mathrm{ppm})=8.17(\mathrm{~s}, 1 \mathrm{H}), 8.12\left(\mathrm{~d},{ }^{3} J=7.8 \mathrm{~Hz}, 1 \mathrm{H}\right), 7.99$ (d, $\left.{ }^{3} J=8.2 \mathrm{~Hz}, 1 \mathrm{H}\right), 7.89(\mathrm{~m}, 1 \mathrm{H}), 7.79(\mathrm{~m}, 1 \mathrm{H})$.

${ }^{13}$ C-NMR (DMSO-d 6 , 75 MHz): $\delta(\mathrm{ppm})=148.6,141.2,135.6,132.7,129.7,129.4,129.3$, 127.3, 126.8 .

IR (ATR): v (cm $\left.{ }^{-1}\right)=3088$ (s), 3060 (vs), 1652 (s), 1562 (s), 1552 (s), 1486 (s), 1452 (m), $1390(\mathrm{~s}), 1262(\mathrm{~m}), 1140(\mathrm{~s}), 1086(\mathrm{~m}), 844(\mathrm{~m}), 808(\mathrm{~m}), 756(\mathrm{~s}), 680(\mathrm{~m})$.

MS (EI, 70 eV): $m / z(\%)=288$ (41), 287 (10), 286 (100), 284 (46), 207 (67), 205 (76), 126 (60).

HR-MS: $\left(\mathrm{C}_{9} \mathrm{H}_{5} \mathrm{Br}_{2} \mathrm{~N}\right)$

calculated 284.8789

found 284.8762

\section{Synthesis of 3,4-dibromoquinoline (9d)}

To a stirred solution of 4-quinolinol (14.3 mmol, $2.08 \mathrm{~g}, 1.0$ equiv) in glacial acetic acid (40 $\mathrm{mL})$, bromine $(0.81 \mathrm{~mL}, 1.1$ equiv) was slowly added. The mixture was refluxed for $24 \mathrm{~h}$, cooled to rt and the 3-bromo-4-quinolinol hydrobromide was collected by filtration, washed with water and dried in vacuo. 3-bromo-4-quinolinol (3.01 g, $94 \%$ ) was obtained as a colourless solid.

mp.: 81.8-83.6 ${ }^{\circ} \mathrm{C}$.

${ }^{1}$ H-NMR (DMSO-d 6 , 400 MHz): $\delta(\mathrm{ppm})=12.24(\mathrm{~s}, 1 \mathrm{H}), 8.44(\mathrm{~s}, 1 \mathrm{H}), 8.11\left(\mathrm{~d},{ }^{3} J=8.0\right.$ $\mathrm{Hz}, 1 \mathrm{H}), 7.68-7.63(\mathrm{~m}, 1 \mathrm{H}), 7.57\left(\mathrm{~d},{ }^{3} \mathrm{~J}=8.2 \mathrm{~Hz}, 1 \mathrm{H}\right), 7.36\left(\mathrm{t},{ }^{3} J=7.4 \mathrm{~Hz}, 1 \mathrm{H}\right)$.

${ }^{13}$ C-NMR (DMSO-d 6 , 100 MHz): $\delta(\mathrm{ppm})=149.1,134.4,127.9,127.7,126.5,126.5,125.1$, 122.7, 105.0.

IR (ATR): $v\left(\mathrm{~cm}^{-1}\right)=3050(\mathrm{~m}), 2968(\mathrm{~m}), 2894(\mathrm{~s}), 2860(\mathrm{~s}), 2792(\mathrm{~s}), 1626(\mathrm{~m}), 1580(\mathrm{~m})$, 1552 (vs), 1504 (vs), 1470 (vs), 1440 (s), 1386 (m), 1354 (s), 1298 (m), 1188 (s), 1136 (m), $836(\mathrm{~m}), 754(\mathrm{~m}), 744(\mathrm{~m}), 688(\mathrm{~m}), 600(\mathrm{~m})$.

MS (EI, 70 eV): $m / z(\%)=224(98)\left[\mathrm{M}^{+},{ }^{81} \mathrm{Br}\right], 222(100)\left[\mathrm{M}^{+},{ }^{79} \mathrm{Br}\right], 144$ (11), $116(27), 115$ (12), 104 (17), 89 (14).

HR-MS: $\left(\mathrm{C}_{9} \mathrm{H}_{6} \mathrm{BrNO}\right)$

calculated 222.9633

found 222.9636

A mixture of 3-bromo-4-quinolinol (13.4 mmol, $3.01 \mathrm{~g}, 1.0$ equiv) and phosphorous tribromide $(12 \mathrm{~mL})$ was refluxed for $5 \mathrm{~h}$. After cooling the reaction mixture was hydrolized by pouring onto crushed ice $(100 \mathrm{~mL})$ and the resulting aq. suspension made strongly alkaline with a solution of sodium hydroxide (32\%). The insoluble product was collected by filtration, washed with water, and dried in vacuo. 3,4-dibromoquinoline was yielded (9d) (3.11 g, 76 \%) as a colourless solid.

mp.: 236.9-239.9 ${ }^{\circ} \mathrm{C}$.

${ }^{1} \mathbf{H}-\mathbf{N M R}\left(\mathbf{C D C l}_{3}, \mathbf{3 0 0} \mathbf{M H z}\right): \delta(\mathrm{ppm})=8.89(\mathrm{~s}, 1 \mathrm{H}), 8.21\left(\mathrm{~d},{ }^{3} J=8.4 \mathrm{~Hz}, 1 \mathrm{H}\right), 8.07\left(\mathrm{~d},{ }^{3} J\right.$ $=8.4 \mathrm{~Hz}, 1 \mathrm{H}), 7.75\left(\mathrm{t},{ }^{3} J=7.5 \mathrm{~Hz}, 1 \mathrm{H}\right), 7.64\left(\mathrm{t},{ }^{3} J=7.7 \mathrm{~Hz}, 1 \mathrm{H}\right)$.

${ }^{13} \mathbf{C}-\mathrm{NMR}\left(\mathbf{C D C l}_{3}, \mathbf{7 5} \mathbf{M H z}\right): \delta(\mathrm{ppm})=151.3,146.7,135.2,130.3,129.9,129.1,128.9$, 127.4, 121.3. 
IR (ATR): v ( $\left.\mathrm{cm}^{-1}\right)=3108$ (s), 3062 (s), 2924 (s), 1818 (m), 1552 (s), 1484 (vs), 1340 (s), $1246(\mathrm{~m}), 1166(\mathrm{~m}), 1106(\mathrm{~m}), 964(\mathrm{~m}), 848(\mathrm{~m}), 808(\mathrm{~m}), 750(\mathrm{~s}), 662(\mathrm{~m}), 628(\mathrm{w}), 594(\mathrm{w})$. MS (EI, 70 eV): $m / z(\%)=288(54)\left[\mathrm{M}^{+}\right.$

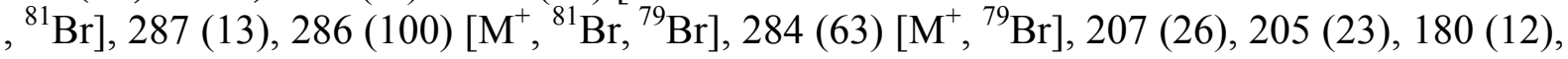
127 (29), 100 (14).

HR-MS: $\left(\mathrm{C}_{9} \mathrm{H}_{5} \mathrm{Br}_{2} \mathrm{~N}\right) \quad$ calculated $284.8789 \quad$ found 284.8769

\section{Synthesis of 2,3,4-tribromoquinoline (9c)}

Prepared according to GP2 from 3,4-dibromoquinoline (9d) (1.0 mmol, $288 \mathrm{mg}, 1.0$ equiv), $\mathrm{TMPMgCl} \cdot \mathrm{LiCl}$ (7) [reaction condition: $-78^{\circ} \mathrm{C}$ for $2 \mathrm{~h}$ ], and 1,2-dibromo-1,1,2,2tetrachloroethane in THF ( $1.3 \mathrm{mmol}, 310 \mathrm{mg}, 1.3$ equiv) [reaction condition: $-78{ }^{\circ} \mathrm{C}$ to $\mathrm{rt}$ for $12 \mathrm{~h}]$. The crude residue was purified by flash-chromatography $\left(\mathrm{SiO}_{2}\right.$, pentane/ether 8:2) yielding 2,3,4-tribromoquinoline (9c) (280 mg, $76 \%$ ) as a colourless solid.

mp.: $132.6-134.2{ }^{\circ} \mathrm{C}$.

${ }^{1} \mathbf{H}-\mathbf{N M R}\left(\mathbf{C D C l}_{3}, \mathbf{3 0 0} \mathbf{M H z}\right): \delta(\mathrm{ppm})=8.20\left(\mathrm{~d},{ }^{3} J=8.4 \mathrm{~Hz}, 1 \mathrm{H}\right), 8.03\left(\mathrm{~d},{ }^{3} J=8.4 \mathrm{~Hz}, 1 \mathrm{H}\right)$, $7.78\left(\mathrm{t},{ }^{3} J=7.6 \mathrm{~Hz}, 1 \mathrm{H}\right), 7.68\left(\mathrm{t},{ }^{3} J=7.7 \mathrm{~Hz}, 1 \mathrm{H}\right)$.

${ }^{13}$ C-NMR (CDCl 3,75 MHz): $\delta(\mathrm{ppm})=146.6,142.8,137.5,131.5,129.5,129.4,128.4$, 128.2, 124.2.

IR (ATR): $v\left(\mathrm{~cm}^{-1}\right)=2358(\mathrm{~m}), 2338(\mathrm{w}), 1552(\mathrm{~s}), 1484(\mathrm{~m}), 1452(\mathrm{~m}), 1354(\mathrm{~m}), 1338(\mathrm{~s})$, $1326(\mathrm{~m}), 1290(\mathrm{~m}), 1246(\mathrm{~m}), 1166(\mathrm{~m}), 1140(\mathrm{w}), 1106(\mathrm{~s}), 964(\mathrm{~m}), 910(\mathrm{w}), 848(\mathrm{~m}), 808$ (m), $752(\mathrm{~s}), 662(\mathrm{~m})$.

MS (EI, 70 eV): $m / z(\%)=368(29)\left[\mathrm{M}^{+},{ }^{81} \mathrm{Br}\right], 366(97)\left[\mathrm{M}^{+},{ }^{81} \mathrm{Br},{ }^{81} \mathrm{Br},{ }^{79} \mathrm{Br}\right], 364(100)$ $\left[\mathrm{M}^{+},{ }^{79} \mathrm{Br},{ }^{79} \mathrm{Br},{ }^{81} \mathrm{Br}\right], 362$ (31) $\left[\mathrm{M}^{+},{ }^{79} \mathrm{Br}\right], 287$ (26), 285 (56), 283 (27), 206 (47), 204 (46), 126 (19), 100 (10), 99 (12).

HR-MS: $\left(\mathrm{C}_{9} \mathrm{H}_{4} \mathrm{Br}_{3} \mathrm{~N}\right) \quad$ calculated: $362.7894 \quad$ found 362.7887

\section{Synthesis of 2-bromo-3-cyanoquinoline (11a)}

Prepared according to GP1 from 2,3-dibromoquinoline (9a) (4.3 mmol, $1.23 \mathrm{~g}, 1.0$ equiv), $i$ $\mathrm{PrMgCl} \cdot \mathrm{LiCl}(4)$ [reaction condition: $-50{ }^{\circ} \mathrm{C}$ for $2 \mathrm{~h}$ ], and tosyl cyanide $(5.6 \mathrm{mmol}, 1.02 \mathrm{~g}$, 1.3 equiv) [reaction condition: $-50{ }^{\circ} \mathrm{C}$ to $\mathrm{rt}$ for $12 \mathrm{~h}$ ]. The crude residue was purified by flashchromatography $\left(\mathrm{SiO}_{2}\right.$, pentane/ether 7:3) yielding 2-bromo-3-cyanoquinoline (11a) $(837 \mathrm{mg}$, $84 \%$ ) as a colourless solid.

mp.: $176.6-177.4{ }^{\circ} \mathrm{C}$.

${ }^{1} \mathbf{H}-\mathrm{NMR}\left(\mathrm{CDCl}_{3}, \mathbf{6 0 0} \mathbf{M H z}\right): \delta(\mathrm{ppm})=8.50(\mathrm{~s}, 1 \mathrm{H}), 8.10\left(\mathrm{~d},{ }^{3} J=8.60 \mathrm{~Hz}, 1 \mathrm{H}\right), 7.93-7.88$ (m, $2 \mathrm{H}), 7.72-7.70(\mathrm{~m}, 1 \mathrm{H})$.

${ }^{13} \mathbf{C}-\mathrm{NMR}\left(\mathbf{C D C l}_{3}, 150 \mathrm{MHz}\right): \delta(\mathrm{ppm})=149.1,144.5,139.7,134.1,129.3,129.0,128.4$, $125.5,116.4,111.1$.

IR (ATR): v (cm $\left.{ }^{-1}\right)=3052(\mathrm{~s}), 2230(\mathrm{~m}), 1612(\mathrm{~m}), 1576(\mathrm{~s}), 1556(\mathrm{~s}), 1486(\mathrm{~s}), 1456(\mathrm{~m})$, 1392 (m), 1370 (s), 1358 (m), 1334 (m), 1132 (s), 1020 (vs), 1010 (s), 970 (m), 936 (s), 774 (m), 760 (vs), $678(\mathrm{~m})$.

MS (EI, 70 eV): $m / z(\%)=233(47)\left[\mathrm{M}^{+},{ }^{81} \mathrm{Br}\right], 231(50)\left[\mathrm{M}^{+},{ }^{79} \mathrm{Br}\right], 153(10), 152(100), 125$ (21).

HR-MS: $\left(\mathrm{C}_{10} \mathrm{H}_{5} \mathrm{BrN}_{2}\right)$

calculated 231.9636

found 231.9640

\section{Synthesis of 1-(2-bromo-quinolin-3-yl)-propan-1-ol (11b)}

Prepared according to GP1 from 2,3-dibromoquinoline (9a) (1.0 mmol, $287 \mathrm{mg}, 1.0$ equiv), $i$-PrMgCl $\mathrm{LiCl}(4)$ [reaction condition: $-50{ }^{\circ} \mathrm{C}$ for $2 \mathrm{~h}$ ], and propionaldehyde $(1.2 \mathrm{mmol}, 70$ 
mg, 1.2 equiv) [reaction condition: $-50{ }^{\circ} \mathrm{C}$ to $\mathrm{rt}$ for $12 \mathrm{~h}$ ]. The crude residue was purified by flash-chromatography $\left(\mathrm{SiO}_{2}\right.$, pentane/ether 7:3) yielding 1-(2-bromo-quinolin-3-yl)-propan-1ol (11b) (202 mg, $76 \%)$ as a colourless solid.

mp.: $85.5-86.7^{\circ} \mathrm{C}$.

${ }^{1} \mathbf{H}-\mathbf{N M R}\left(\mathbf{C D C l}_{3}, 300 \mathbf{M H z}\right): \delta(\mathrm{ppm})=8.21(\mathrm{~s}, 1 \mathrm{H}), 7.95(\mathrm{~d}, 7.9 \mathrm{~Hz}, 1 \mathrm{H}), 7.72(\mathrm{~d}, 7.9 \mathrm{~Hz}$ ,1H), $7.64\left(\mathrm{td},{ }^{3} J=7.1 \mathrm{~Hz},{ }^{4} J=1.1 \mathrm{~Hz}, 1 \mathrm{H}\right), 7.50\left(\mathrm{td},{ }^{3} J=7.1 \mathrm{~Hz},{ }^{4} J=1.3 \mathrm{~Hz}, 1 \mathrm{H}\right), 5.07-$ $5.03(\mathrm{dd}, J=3.8 \mathrm{~Hz}, J=8.0 \mathrm{~Hz}, 1 \mathrm{H}), 2.98(\mathrm{~s}, 1 \mathrm{H}), 1.98-1.97(\mathrm{~m}, 1 \mathrm{H}), 1.77-1.62(\mathrm{~m}, 1 \mathrm{H}), 1.03$ (t, $J=7.5 \mathrm{~Hz}, 3 \mathrm{H})$.

${ }^{13} \mathbf{C}-\mathbf{N M R}\left(\mathbf{C D C l}_{3}, 75 \mathbf{M H z}\right): \delta(\mathrm{ppm})=193.5,147.4,141.9,138.2,135.3,130.1,128.0$, 127.7, 127.4, 73.1, 30.7, 10.0.

IR (ATR): $v\left(\mathrm{~cm}^{-1}\right)=3273(\mathrm{~s}), 2964(\mathrm{w}), 2928(\mathrm{w}), 1587(\mathrm{~m}), 1489(\mathrm{~m}), 1330(\mathrm{~s}), 1172(\mathrm{~m})$, $1128(\mathrm{~m}), 1101$ (s), $1019(\mathrm{~m}), 1008(\mathrm{~m}), 976(\mathrm{~s}), 776(\mathrm{~s}), 750$ (s).

MS (EI, 70 eV): $m / z(\%)=267(8)\left[\mathrm{M}^{+},{ }^{81} \mathrm{Br}\right], 265(8)\left[\mathrm{M}^{+},{ }^{79} \mathrm{Br}\right], 238$ (97), $236(100), 156$ (62), 128 (61), 101 (15), 77 (4).

HR-MS: $\left(\mathrm{C}_{12} \mathrm{H}_{12} \mathrm{BrNO}\right)$

calculated 265.0102

found 265.0103

\section{Synthesis of 2-bromo-4-phenylsulfanyl-quinoline (11c)}

Prepared according to GP1 from 2,4-dibromoquinoline (9b) in THF (1.0 mmol, $287 \mathrm{mg}, 1.0$ equiv), $i$-PrMgCl$\cdot \mathrm{LiCl}(4)$ [reaction condition: $-78^{\circ} \mathrm{C}$ for $2 \mathrm{~h}$ ], and benzenethiosulfonic acid $S$-phenyl ester ${ }^{6}\left(1.2 \mathrm{mmol}, 300 \mathrm{mg}, 1.2\right.$ equiv) [reaction condition: $-50{ }^{\circ} \mathrm{C}$ to $\mathrm{rt}$ for $12 \mathrm{~h}$ ].

The crude residue was purified by flash-chromatography $\left(\mathrm{SiO}_{2}\right.$, pentane/ether 4:1) yielding 2bromo-4-phenylsulfanyl-quinoline (11c) $(286 \mathrm{mg}, 91 \%)$ as a yellow solid.

mp.: $89.0-91.7^{\circ} \mathrm{C}$.

${ }^{1}$ H-NMR $\left(\mathbf{C D C l}_{3}, \mathbf{3 0 0} \mathbf{M H z}\right): \delta(\mathrm{ppm})=8.17(\mathrm{~d}, J=8.4 \mathrm{~Hz}, 1 \mathrm{H}), 8.02(\mathrm{~d}, J=8.4 \mathrm{~Hz}, 1 \mathrm{H})$, $7.74\left(\mathrm{td},{ }^{3} J=8.4 \mathrm{~Hz},{ }^{4} J=1.5 \mathrm{~Hz}, 1 \mathrm{H}\right), 7.63-7.49(\mathrm{~m}, 6 \mathrm{H}), 6.77(\mathrm{~s}, 1 \mathrm{H})$.

${ }^{13}$ C-NMR $\left(\mathbf{C D C l}_{3}, 75 \mathbf{~ M H z}\right): \delta(\mathrm{ppm})=151.8,147.6,141.5,135.5,135.5,130.9,130.3$, $130.3,129.1,128.2,126.9,124.6,123.5,120.8$.

IR (ATR): $v\left(\mathrm{~cm}^{-1}\right)=3056(\mathrm{w}), 3044(\mathrm{w}), 1956(\mathrm{w}), 1724(\mathrm{w}), 1544(\mathrm{~m}), 1488(\mathrm{~m}), 1440$

(m), 1384 (m), 1252 (m), 1140 (s), 1100 (m), 976 (m), 852 (m), 824 (s), 780 (m), 752 (vs), $688(\mathrm{~s})$.

MS (EI, 70 eV): $m / z(\%)=316(81)\left[\mathrm{M}^{+},{ }^{81} \mathrm{Br}\right], 314(81)\left[\mathrm{M}^{+},{ }^{79} \mathrm{Br}\right], 236(100), 208(11)$, 204(13), 190 (10), 166 (20), 159 (10), 127 (18), 117 (14), 108 (30), 104 (14), 101(14), 77 (17), 75 (21), 68 (15), 65 (26), 51 (28).

HR-MS: $\left(\mathrm{C}_{15} \mathrm{H}_{10} \mathrm{BrNS}\right) \quad$ calculated for $[\mathrm{M}-\mathrm{H}]^{+} 315.9791$

found 315.9796

\section{Synthesis of 2-bromoquinoline-4-carbonitrile (11d)}

Prepared according to GP1 from 2,4-dibromoquinoline (9b) in THF (1 mL) (1.0 mmol, 287 mg, 1.0 equiv), $i-\mathrm{PrMgCl} \cdot \mathrm{LiCl}(4)$ [reaction condition: $-78^{\circ} \mathrm{C}$ for $2 \mathrm{~h}$ ], and tosyl cyanide (1.2 mmol, $220 \mathrm{mg}, 1.2$ equiv) [reaction condition: $-50{ }^{\circ} \mathrm{C}$ for $30 \mathrm{~min}$ and warmed to $\mathrm{rt}$ for 6 h]. The crude residue was purified by flash-chromatography $\left(\mathrm{SiO}_{2}\right.$, pentane/ether 2:3) yielding 2-bromoquinoline-4-carbonitrile (11d) (196 mg, 85\%) as a colourless solid.

mp.: $153.0-155.5^{\circ} \mathrm{C}$.

${ }^{1}$ H-NMR (CDCl $\left.3,300 \mathbf{M H z}\right): \quad \delta(\mathrm{ppm})=8.15(\mathrm{t}, J=8.8 \mathrm{~Hz}, 2 \mathrm{H}), 7.88(\mathrm{td}, J=8.4 \mathrm{~Hz}, J=$ $1.3 \mathrm{~Hz}, 1 \mathrm{H}), 7.85(\mathrm{~s}, 1 \mathrm{H}), 7.78$ (td, $J=8.2 \mathrm{~Hz}, J=1.3 \mathrm{~Hz}, 1 \mathrm{H})$.

${ }^{13} \mathbf{C}-\mathrm{NMR}\left(\mathbf{C D C l}_{3}, \mathbf{7 5} \mathbf{M H z}\right): \quad \delta(\mathrm{ppm})=148.4,140.1,132.3,129.5,129.5,129.4,125.1$, 124.6, 120.8, 114.2.

${ }^{6}$ Fujiki, K.; Tanifuji, N.; Sasaki, Y.; Yokoyama, T. Synthesis 2002, 343. 
IR (ATR): v ( $\left.\mathrm{cm}^{-1}\right)=3055(\mathrm{w}), 2235(\mathrm{w}), 1571(\mathrm{w}), 1539(\mathrm{~m}), 1495(\mathrm{w}), 1408(\mathrm{w}), 1279$ (m), $1223(\mathrm{w}), 1146(\mathrm{~m}), 1088(\mathrm{~s}), 891(\mathrm{~m}), 866(\mathrm{~s}), 853(\mathrm{~m}), 762(\mathrm{~s})$.

MS (EI, 70 eV): $m / z(\%)=233(71)\left[\mathrm{M}^{+},{ }^{81} \mathrm{Br}\right], 231(74)\left[\mathrm{M}^{+},{ }^{79} \mathrm{Br}\right], 152$ (100), 125 (14), 99 (2), $76(1)$.

HR-MS: $\left(\mathrm{C}_{10} \mathrm{H}_{5} \mathrm{BrN}_{2}\right)$

calculated 231.9636

found 231.9614

\section{Synthesis of 2-bromoquinolin-4-ylamine (11e)}

Prepared according to GP1 from 2,4-dibromoquinoline (9b) in THF (1 mL) (1.0 mmol, 287 mg, 1.0 equiv), $i$-PrMgCl $\cdot \mathrm{LiCl}$ (4) [reaction condition: $-78{ }^{\circ} \mathrm{C}$ for $2 \mathrm{~h}$ ]. To the freshly prepared magnesium reagent, $\mathrm{CuCl} \cdot 2 \mathrm{LiCl}(1.2 \mathrm{~mL}, 1.0 \mathrm{M}$ in $\mathrm{THF}, 1.2 \mathrm{mmol})$ was added dropwise at $-50{ }^{\circ} \mathrm{C}$ under argon and the mixture was stirred for $1 \mathrm{~h}$. To the formed aryl copper reagent, commercially available LiHMDS (1M in THF/Ethylbenzene) $(2 \mathrm{mmol}, 2 \mathrm{~mL}, 2$ equiv) was added dropwise and the mixture was further stirred for $1 \mathrm{~h}$ at $-60{ }^{\circ} \mathrm{C}$. The reaction mixture was cooled to $-78{ }^{\circ} \mathrm{C}$, then a solution of chloranil $(298 \mathrm{mg}, 1.2 \mathrm{mmol})$ in dry THF (7 $\mathrm{mL}$ ) was added slowly over a period of $1 \mathrm{~h}$ at $-78{ }^{\circ} \mathrm{C}$. The reaction mixture was then stirred for further $12 \mathrm{~h}$. $\mathrm{Et}_{2} \mathrm{O}(10 \mathrm{~mL})$ was poured into the crude reaction mixture. The resulting mixture was then filtered through celite and the residue washed with $\mathrm{Et}_{2} \mathrm{O}$ (ca. $100 \mathrm{~mL}$ ). The organic phase was washed with $2 \times 10 \mathrm{~mL}$ portions of aqueous $\mathrm{NH}_{4} \mathrm{OH}(2.0 \mathrm{M})$ and extracted with $\mathrm{Et}_{2} \mathrm{O}$. The combined organic layers were dried $\left(\mathrm{MgSO}_{4}\right)$, filtered, and concentrated under reduced pressure. The crude material obtained was redissolved in THF $(3 \mathrm{~mL})$ before TBAF (1.0 $\mathrm{m}$ in THF) ( $2 \mathrm{~mL}, 2 \mathrm{mmol})$ was added in one portion and the mixture was stirred at room temperature for $15 \mathrm{~min}$, poured over EtOAc $(10 \mathrm{~mL})$ and washed with deionised water $(3 \times 10$ $\mathrm{mL})$. The combined organic extracts were dried $\left(\mathrm{MgSO}_{4}\right)$, filtered and concentrated in vacuum. Purification by flash-chromatography $\left(\mathrm{SiO}_{2}\right.$, pentane/ether 9:1 with $\left.0.5 \% \mathrm{NEt}_{3}\right)$ yielding 2-bromoquinolin-4-ylamine (11e) $(166 \mathrm{mg}, 75 \%)$ as a pale yellowish solid.

mp.: $191.9-193.3^{\circ} \mathrm{C}$.

${ }^{1}$ H-NMR (DMSO-d 6 , 400 MHz): $\delta(\mathrm{ppm})=8.13(\mathrm{~d}, J=9.1 \mathrm{~Hz}, 1 \mathrm{H}), 7.68-7.61(\mathrm{~m}, 2 \mathrm{H})$, 7.45-7.41 (m, 1H), $7.14(\mathrm{~s}, 2 \mathrm{H}), 6.64(\mathrm{~s}, 1 \mathrm{H})$.

${ }^{13}$ C-NMR (DMSO-d 6 , 100 MHz): $\delta(\mathrm{ppm})=153.7,148.4,142.2,130.2,127.8,124.4,122.6$, 117.8, 104.1.

IR (ATR): $v\left(\mathrm{~cm}^{-1}\right)=3456(\mathrm{~m}), 3310(\mathrm{~m}), 3195(\mathrm{br}), 2923(\mathrm{w}), 1685(\mathrm{~s}), 1574(\mathrm{~s}), 1549$ (s), 1511 (s), 1439 (s), 1351 (m), 1322 (m), 1143 (m), 1106 (m), 907 (s), 816 (m), 808 (m), 752 (s).

MS (EI, 70 eV): $m / z(\%)=223(73)\left[\mathrm{M}^{+},{ }^{81} \mathrm{Br}\right], 221(82)\left[\mathrm{M}^{+},{ }^{79} \mathrm{Br}\right], 143$ (47), $116(100), 115$ (12), 89 (22), $76(5), 63$ (5), 50 (5).

HR-MS: $\left(\mathrm{C}_{9} \mathrm{H}_{7}{ }^{79} \mathrm{BrN}_{2}\right) \quad$ calculated 221.9793

found 221.9786

\section{Synthesis of 2,4-dibromo-quinoline-3-carbonitrile (11f)}

Prepared according to GP1 from 2,3,4-tribromoquinoline (9c) in THF (1 mL) (1.0 mmol, 365 $\mathrm{mg}, 1.0$ equiv), $\mathrm{MesMgBr} \cdot \mathrm{LiCl}(5)$ [reaction condition: $-10^{\circ} \mathrm{C}$ for $3 \mathrm{~h}$ ], and tosyl cyanide (1.2 mmol, $220 \mathrm{mg}, 1.2$ equiv) [reaction condition: $-50{ }^{\circ} \mathrm{C}$ for $30 \mathrm{~min}$ and warmed to $\mathrm{rt}$ for 6 h]. The crude residue was purified by flash-chromatography $\left(\mathrm{SiO}_{2}\right.$, pentane/ether 9:1) yielding 2,4-dibromoquinoline-3-carbonitrile (11f) $\quad(274 \mathrm{mg}, \quad 88 \%)$ as colourless needles (recrystallization ether/AcOEt 1:1).

mp.: 207.1- $208.1^{\circ} \mathrm{C}$.

${ }^{1} \mathbf{H}-\mathbf{N M R}\left(\mathbf{C D C l}_{3}, \mathbf{3 0 0} \mathbf{M H z}\right): \delta(\mathrm{ppm})=8.22(\mathrm{~d}, J=8.6 \mathrm{~Hz}, 1 \mathrm{H}), 8.07(\mathrm{~d}, J=8.4 \mathrm{~Hz}, 1 \mathrm{H})$, $7.93(\mathrm{t}, J=8.2 \mathrm{~Hz}, 1 \mathrm{H}), 7.78(\mathrm{t}, J=8.2 \mathrm{~Hz}, 1 \mathrm{H})$.

${ }^{13}$ C-NMR $\left(\mathbf{C D C l}_{3}, \mathbf{7 5 M H z}\right): \delta(\mathrm{ppm})=148.3,141.7,139.3,134.3,129.8,129.5,128.1$, 125.8, 115.6, 114.4. 
IR (ATR): $v\left(\mathrm{~cm}^{-1}\right)=3059(\mathrm{w}), 3038(\mathrm{w}), 2226(\mathrm{w}), 1544(\mathrm{~m}), 1474(\mathrm{~m}), 1376(\mathrm{w}), 1354$ (w), 1298 (m), 1203 (w), 1136 (w), 1033 (m), 912 (m), 871 (m), 757 (s), 731 (s).

MS (EI, 70 eV): $m / z(\%)=313$ (28), 311 (57), 309 (28), 232 (50), 230 (48), 152 (100), 125 (15), 99 (30), 75 (19), 51 (11).

HR-MS: $\left(\mathrm{C}_{10} \mathrm{H}_{4} \mathrm{Br}_{2} \mathrm{~N}_{2}\right)$

calculated $[\mathrm{M}-\mathrm{H}]^{+} 310.8820$

found 310.8818

\section{Synthesis of 2,4-dibromo-quinoline-3-carboxylic acid ethyl ester (11g)}

Prepared according to GP1 from 2,3,4-tribromoquinoline (9c) in THF (1 mL) (1.0 mmol, 365 $\mathrm{mg}, 1.0$ equiv), MesMgBr$\cdot \mathrm{LiCl}$ (5) [reaction condition: $-10{ }^{\circ} \mathrm{C}$ for $3 \mathrm{~h}$ ], and ethyl cyanoformate $\left(1.2 \mathrm{mmol}, 119 \mathrm{mg}, 1.2\right.$ equiv) [reaction condition: $-50{ }^{\circ} \mathrm{C}$ for $30 \mathrm{~min}$ and warmed to $\mathrm{rt}$ for $6 \mathrm{~h}]$. The crude residue was purified by flash-chromatography $\left(\mathrm{SiO}_{2}\right.$, pentane/ether 9:1) yielding 2,4-dibromo-quinoline-3-carboxylic acid ethyl ester (11g) (320 $\mathrm{mg}, 90 \%)$ as a colourless solid.

mp.: $107.8-111.8^{\circ} \mathrm{C}$.

${ }^{1} \mathbf{H}-\mathbf{N M R}\left(\mathbf{C D C l}_{3}, 300 \mathrm{MHz}\right): \delta(\mathrm{ppm})=8.19(\mathrm{~d}, J=8.4 \mathrm{~Hz}, 1 \mathrm{H}), 8.03(\mathrm{~d}, J=8.4 \mathrm{~Hz}, 1 \mathrm{H})$, $7.80(\mathrm{td}, J=7.1 \mathrm{~Hz}, J=1.5 \mathrm{~Hz}, 1 \mathrm{H}), 7.69$ (td, $J=7.2 \mathrm{~Hz}, J=1.5 \mathrm{~Hz}, 1 \mathrm{H}), 4.53$ (q, $J=7.3 \mathrm{~Hz}$, $2 \mathrm{H}), 1.46(\mathrm{t}, J=7.3 \mathrm{~Hz}, 3 \mathrm{H})$.

${ }^{13} \mathbf{C}-\mathbf{N M R}\left(\mathbf{C D C l}_{3}, \mathbf{7 5} \mathbf{~ M H z}\right): \delta(\mathrm{ppm})=165.1,147.9,136.2,132.5,132.2,132.1,129.1$, 129.0,127.3, 126.1, 62.9, 14.0.

IR (ATR): $v\left(\mathrm{~cm}^{-1}\right)=2983(\mathrm{w}), 1731(\mathrm{~s}), 1692(\mathrm{w}), 1552(\mathrm{~s}), 1476(\mathrm{~m}), 1377(\mathrm{~m}), 1354(\mathrm{~m})$, 1319 (m), 1295 (m), 1243 (m), 1230 (s), 1179 (s), 1130 (m), 1018 (m), 919 (m), 857 (w), 808 (m), $746(\mathrm{~s}), 679(\mathrm{~s})$.

MS (EI, 70 eV): $m / z(\%)=317$ (80), 236 (100), 204 (13), 190 (10), 165 (19), 127 (18), 117 (14), 109 (14), 77 (17), 75 (20), 65 826), 51 (28).

HR-MS: $\left(\mathrm{C}_{12} \mathrm{H}_{9} \mathrm{Br}_{2} \mathrm{NO}_{2}\right)$ calculated $[\mathrm{M}-\mathrm{H}]^{+} 357.9079$ found 357.9078

\section{Synthesis of 4-Bromo-3-methylsulfanylquinoline (11h)}

A dry and argon flushed flask, equipped with a magnetic stirring bar and a septum, was charged with $\mathrm{Mes}_{2} \mathrm{Mg} \cdot 2 \mathrm{LiBr}(6)(1.1 \mathrm{mmol}, 1.1$ equiv, $0.62 \mathrm{M}$ of $[\mathrm{Mg}]$ in THF) and TMEDA $\left(0.18 \mathrm{~mL}, 1.1 \mathrm{mmol}, 1.1\right.$ equiv) and stirred at $-10^{\circ} \mathrm{C}$ for $10 \mathrm{~min}$. Thereafter, a solution of 3,4dibromoquinoline (9d) $(1.0 \mathrm{mmol}, 287 \mathrm{mg}, 1.0$ equiv) in dry THF (1 mL) was added slowly, dropwise, at $-10^{\circ} \mathrm{C}$ and stirred for $6 \mathrm{~h}$. The completion of the $\mathrm{Br} / \mathrm{Mg}$ exchange was checked by GC-analysis using decane as internal standard. To the freshly prepared red magnesium reagent was added benzenethiosulfonic acid $S$-methyl ester ${ }^{7}$ ( $244 \mathrm{mg}, 1.3 \mathrm{mmol}, 1.3$ equiv) at $-10{ }^{\circ} \mathrm{C}$ and the mixture was then stirred and warmed to $\mathrm{rt}$ for $6 \mathrm{~h}$. After the reaction was completed, sat. $\mathrm{NH}_{4} \mathrm{Cl}$ solution was added and the mixture was extracted three times with $\mathrm{CH}_{2} \mathrm{Cl}_{2}$. The solvent was evaporated and the product was purified by flash-chromatography $\left(\mathrm{SiO}_{2}\right.$, pentane/ether 1:1) yielding 4-bromo-3-methylsulfanylquinoline (11h) (199 mg, 79\%) as a colourless solid.

mp.: 105.0 - $109.2{ }^{\circ} \mathrm{C}$.

${ }^{1}$ H-NMR $\left(\mathbf{C D C l}_{3}, 300 \mathrm{MHz}\right): \delta(\mathrm{ppm})=8.69(\mathrm{~s}, 1 \mathrm{H}), 8.15(\mathrm{~d}, J=8.4 \mathrm{~Hz}, 1 \mathrm{H}), 8.05(\mathrm{~d}, J=$ $8.2 \mathrm{~Hz}, 1 \mathrm{H}), 7.71-7.59(\mathrm{~m}, 2 \mathrm{H}), 2.56(\mathrm{~s}, 3 \mathrm{H})$.

${ }^{13} \mathbf{C}-\mathbf{N M R}\left(\mathbf{C D C l}_{3}, 75 \mathbf{M H z}\right): \delta(\mathrm{ppm})=147.1,146.2,133.7,132.3,129.7,129.2,128.4$, $127.8,126.1,16.3$.

IR (ATR): $v\left(\mathrm{~cm}^{-1}\right)=2921(\mathrm{w}), 1612(\mathrm{w}), 1545(\mathrm{~m}), 1483(\mathrm{~s}), 1473(\mathrm{~s}), 1432(\mathrm{~m}), 1331(\mathrm{~s})$, 1320 (s), 1253 (m), 1163 (m), 1111 (s), 952 (m), 931 (m), 871 (m), 810 (s), 750 (s), 667 (s). 
MS (EI, 70 eV): $m / z(\%)=254(100)\left[\mathrm{M}^{+},{ }^{81} \mathrm{Br}\right], 252(98)\left[\mathrm{M}^{+},{ }^{79} \mathrm{Br}\right], 239$ (10), 237 (9), 173 (10), 159 (34), 132 (8), 87 (7).

HR-MS: $\left(\mathrm{C}_{10} \mathrm{H}_{8} \mathrm{BrNS}\right)$

calculated 252.9561

found 252.9540

\section{Synthesis of 4-(4-bromoquinolin-3-yl)-benzonitrile (11i)}

A dry and argon flushed flask, equipped with a magnetic stirring bar and a septum, was charged with $\mathrm{Mes}_{2} \mathrm{Mg} \cdot 2 \mathrm{LiBr}(6)(1.1 \mathrm{mmol}, 1.8 \mathrm{~mL}, 1.1$ equiv, $0.62 \mathrm{M}$ of $[\mathrm{Mg}]$ in THF) and TMEDA $\left(0.18 \mathrm{~mL}, 1.1 \mathrm{mmol}, 1.1\right.$ equiv) and stirred at $-10{ }^{\circ} \mathrm{C}$ for $10 \mathrm{~min}$. Thereafter, a solution of 3,4-dibromoquinoline (9d) $(1.0 \mathrm{mmol}, 287 \mathrm{mg}, 1.0$ equiv) in dry THF (1 mL) was added slowly dropwise at $-10^{\circ} \mathrm{C}$ and stirred for $6 \mathrm{~h}$. The completion of the $\mathrm{Br} / \mathrm{Mg}$ exchange was checked by GC-analysis using decane as internal standard. The corresponding freshly prepared red magnesium reagent was transmetalated with $\mathrm{ZnCl}_{2}(1.1 \mathrm{~mL}, 1.1$ equiv, $1 \mathrm{M}$ in dry THF) and the mixture was warmed to rt for $1 \mathrm{~h}$. 4-iodobenzonitrile (297 mg, $1.3 \mathrm{mmol}$, 1.3 equiv) was then added neat to the reaction mixture. A flame-dried round bottom flask was charged with $\mathrm{Pd}(\mathrm{dba})_{2}(30 \mathrm{mg}, 5 \mathrm{~mol} \%), \mathrm{P}(o \text {-furyl })_{3}(24 \mathrm{mg}, 10 \mathrm{~mol} \%)$ and THF $(1 \mathrm{~mL})$. The mixture was stirred at $25{ }^{\circ} \mathrm{C}$ for $10 \mathrm{~min}$, then transferred to the reaction flask which was charged with the organozinc solution. The resulting mixture was stirred $12 \mathrm{~h}$ at rt, quenched with sat. aq. $\mathrm{NH}_{4} \mathrm{Cl}$ and extracted three times with AcOEt. The solvent was evaporated and the product was purified by flash-chromatography $\left(\mathrm{SiO}_{2}\right.$, pentane/ether 1:1) yielding 4-(4bromoquinolin-3-yl)-benzonitrile (11i) $(219 \mathrm{mg}, 71 \%)$ as a colourless solid.

mp.: $160.0-162.7^{\circ} \mathrm{C}$.

${ }^{1} \mathbf{H}-\mathbf{N M R}\left(\mathbf{C D C l}_{3}, \mathbf{3 0 0} \mathbf{M H z}\right): \delta(\mathrm{ppm})=8.71(\mathrm{~s}, 1 \mathrm{H}), 8.32(\mathrm{~d}, J=7.9 \mathrm{~Hz}, 1 \mathrm{H}), 8.16(\mathrm{~d}, 7.9$ $\mathrm{Hz}, 1 \mathrm{H})$, 7.84-7.60 (m, 6H).

${ }^{13}$ C-NMR (CDCl 3 , 75 MHz): $\delta(\mathrm{ppm})=149.9,148.1,142.8,134.3,133.6,132.2$ (2C), 130.7 (3C), 129.8, 128.7, 127.5 (2C), 118.4, 112.4.

IR (ATR): $v\left(\mathrm{~cm}^{-1}\right)=2978(\mathrm{w}), 2230(\mathrm{w}), 1724(\mathrm{~m}), 1690(\mathrm{w}), 1603(\mathrm{w}), 1548(\mathrm{~m}), 1476(\mathrm{~s})$, $1337(\mathrm{~m}), 1077(\mathrm{~m}), 1022(\mathrm{w}), 958(\mathrm{w}), 871(\mathrm{w}), 839(\mathrm{~s}), 759(\mathrm{~s}), 671(\mathrm{~s})$.

MS (EI, 70 eV): $m / z(\%)=309(100)\left[\mathrm{M}^{+},{ }^{81} \mathrm{Br}\right], 307(94)\left[\mathrm{M}^{+},{ }^{79} \mathrm{Br}\right], 230$ (17), 229 (86), 228 (14), 201 (38), 175 (22), 114 (14), 101 (16), 88 (5), 75 (4).

HR-MS: $\left(\mathrm{C}_{16} \mathrm{H}_{9}{ }^{81} \mathrm{BrN}_{2}\right) \quad$ calculated 309.9949 found 309.9911

\section{Synthesis of 3-benzyl-2,4-dibromoquinoline (11j)}

Prepared according to GP1 from 2,3,4-tribromoquinoline (9c) (5.0 mmol, $1.82 \mathrm{~g}, 1.0$ equiv) dissolved in dry THF $(5 \mathrm{~mL}), \mathrm{MesMgBr} \cdot \mathrm{LiCl}(5)$ [reaction condition: $-10^{\circ} \mathrm{C}$ for $3 \mathrm{~h}$ ], and benzyl bromide $\left(1.4 \mathrm{mmol}, 1.19 \mathrm{~g}, 1.4\right.$ equiv) [reaction condition: $-50^{\circ} \mathrm{C}$ for $30 \mathrm{~min}$ and warmed to $\mathrm{rt}$ for $20 \mathrm{~h}$ ]. The crude residue was purified by flash-chromatography $\left(\mathrm{SiO}_{2}\right.$, pentane/ether 3:2) yielding 3-benzyl-2,4-dibromoquinoline (11j) $(1.67 \mathrm{~g}, 89 \%)$ as a colourless solid.

mp.: $99.2-100.6{ }^{\circ} \mathrm{C}$.

${ }^{1} \mathbf{H}-\mathbf{N M R}\left(\mathbf{C D C l}_{3}, 300 \mathrm{MHz}\right): \delta(\mathrm{ppm})=8.22(\mathrm{~d}, J=8.8 \mathrm{~Hz}, 1 \mathrm{H}), 8.03(\mathrm{~d}, J=8.3 \mathrm{~Hz}, 1 \mathrm{H})$, $7.74(\mathrm{td}, J=7.1 \mathrm{~Hz}, J=1.5 \mathrm{~Hz}, 1 \mathrm{H}), 7.66(\mathrm{td}, J=7.0 \mathrm{~Hz}, J=1.5 \mathrm{~Hz}, 1 \mathrm{H}), 7.30-7.17$ (m, 5H), $4.65(\mathrm{~s}, 2 \mathrm{H})$.

${ }^{13} \mathbf{C}-\mathrm{NMR}\left(\mathbf{C D C l}_{3}, \mathbf{7 5} \mathbf{M H z}\right): \delta(\mathrm{ppm})=147.2,144.6,137.2,137.0,134.5,130.7,128.9$, $128.5,128.5,128.4,128.3,128.3,127.6,127.5,126.5,42.1$.

IR (ATR): v $\left(\mathrm{cm}^{-1}\right)=3028(\mathrm{w}), 2924(\mathrm{w}), 1600(\mathrm{w}), 1552(\mathrm{~s}), 1491(\mathrm{w}), 1475(\mathrm{~s}), 1451(\mathrm{~m})$, 1354 (m), 1299 (m), 1135 (m), 1027 (m), 1016 (m), 908 (m), 879 (m), 762 (s), 722 (s), 693 (s). 
MS (EI, 70 eV): $m / z(\%)=376$ (14), 295 (10), 217 (37), 216 (100), 215 (11), 189 (12), 140 (7), 107 (14), 94 (10), 63 (7), 51 (7).

HR-MS: $\left(\mathrm{C}_{16} \mathrm{H}_{11} \mathrm{Br}_{2} \mathrm{~N}\right) \quad$ calculated $[\mathrm{M}-\mathrm{H}]^{+} 375.9337 \quad$ found 375.9333

\section{Synthesis of 2-Bromo-quinoline-3-carboxylic acid ethyl ester (11k)}

Prepared according to GP 1 from 2,3-dibromoquinoline (9a) (4.0 mmol, $1.15 \mathrm{~g}, 1.0$ equiv), $i$ $\mathrm{PrMgCl} \cdot \mathrm{LiCl}$ (4) [reaction condition: $-50^{\circ} \mathrm{C}$ for $2 \mathrm{~h}$ ], and ethyl cyanoformate $(4.8 \mathrm{mmol}$, $475 \mathrm{mg}, 1.2$ equiv) [reaction condition: $-50^{\circ} \mathrm{C}$ to $\mathrm{rt}$ for $5 \mathrm{~h}$ ]. The crude residue was purified by flash-chromatography $\left(\mathrm{SiO}_{2}\right.$, pentane/ether 7:3) yielding 2-bromoquinoline-3-carboxylic acid ethyl ester (11k) $(984 \mathrm{mg}, 88 \%)$ as a colourless solid.

mp.: $104.1-107.2^{\circ} \mathrm{C}$.

${ }^{1} \mathbf{H}-\mathbf{N M R}\left(\mathbf{C D C l}_{3}, 300 \mathrm{MHz}\right): \delta(\mathrm{ppm})=8.55(\mathrm{~s}, 1 \mathrm{H}), 8.06(\mathrm{~d}, J=8.6 \mathrm{~Hz}, 1 \mathrm{H}), 7.87(\mathrm{~d}, J=$ $8.2 \mathrm{~Hz}, 1 \mathrm{H}), 7.81(\mathrm{td}, J=7.1 \mathrm{~Hz}, J=1.5 \mathrm{~Hz}, 1 \mathrm{H}), 7.62(\mathrm{td}, J=8.1 \mathrm{~Hz}, J=1.1 \mathrm{~Hz}, 1 \mathrm{H}), 4.47$ $(\mathrm{q}, J=7.3 \mathrm{~Hz}, 2 \mathrm{H}), 1.45(\mathrm{t}, J=7.3 \mathrm{~Hz}, 3 \mathrm{H})$.

${ }^{13}$ C-NMR (CDCl 3 , 75 MHz): $\delta(\mathrm{ppm})=165.1,148.8,140.4,138.5,132.4,128.6,128.4$, 127.9, 126.9, 25.9, 62.2, 14.2 .

IR (ATR): $v\left(\mathrm{~cm}^{-1}\right)=3056(\mathrm{w}), 2980(\mathrm{w}), 2928(\mathrm{w}), 1724(\mathrm{~s}), 1480(\mathrm{~m}), 1388(\mathrm{~m}), 1368(\mathrm{~m})$, 1268 (m), 1264 (m), 1244 (s), 1228 (s), 1196 (s), 1124 (s), 1112 (s), 1028 (s), 996 (s), 936 (s), $876(\mathrm{~s}), 816(\mathrm{~m}), 780$ (vs), 752 (vs).

MS (EI, 70 eV): $m / z(\%)=281$ (12), 279 (13), 278 (100), 252 (24), 250 (25), 235 (73), 233 (74), 207 (17), 205 (17), 172 (20), 128 (12).

HR-MS: $\left(\mathrm{C}_{12} \mathrm{H}_{10} \mathrm{BrNO}_{2}\right) \quad$ calculated $278.9895 \quad$ found 278.9956

\section{Synthesis of ethyl 2-bromoquinoline-4-carboxylate (11)}

Prepared according to GP1 from 2,4-dibromoquinoline (9a) (8 mmol, $2.3 \mathrm{~g}, 1.0$ equiv) dissolved in THF $(10 \mathrm{~mL}), i$-PrMgCl$\cdot \mathrm{LiCl}(4)$ [reaction condition: $-78^{\circ} \mathrm{C}$ for $2 \mathrm{~h}$ ], and ethyl cyanoformate $\left(9.6 \mathrm{mmol}, 950 \mathrm{mg}, 1.2\right.$ equiv) [reaction condition: $-78^{\circ} \mathrm{C}$ to $\mathrm{rt}$ for $12 \mathrm{~h}$ ].

The crude residue was purified by flash-chromatography $\left(\mathrm{SiO}_{2}\right.$, pentane/ether 4:1) yielding ethyl 2-bromoquinoline-4-carboxylate (11l) $(2.06 \mathrm{~g}, 92 \%)$ as a colourless solid.

mp.: $74.3-76.9^{\circ} \mathrm{C}$.

${ }^{1} \mathbf{H}-N M R\left(\mathbf{C D C l}_{3}, 300 \mathrm{MHz}\right): \delta(\mathrm{ppm})=8.71\left(\mathrm{~d},{ }^{3} \mathrm{~J}=8.4 \mathrm{~Hz}, 1 \mathrm{H}\right), 8.07\left(\mathrm{~d},{ }^{3} \mathrm{~J}=8.4 \mathrm{~Hz}\right.$, $1 \mathrm{H}), 8.00(\mathrm{~s}, 1 \mathrm{H}), 7.77\left(\mathrm{td},{ }^{3} \mathrm{~J}=7.1 \mathrm{~Hz},{ }^{4} \mathrm{~J}=1.3 \mathrm{~Hz}, 1 \mathrm{H}\right), 7.65\left(\mathrm{td},{ }^{3} \mathrm{~J}=7.1 \mathrm{~Hz},{ }^{4} \mathrm{~J}=1.3 \mathrm{~Hz}, 1\right.$ $\mathrm{H}), 4.50\left(\mathrm{q},{ }^{3} \mathrm{~J}=7.2 \mathrm{~Hz}, 2 \mathrm{H}\right), 1.47\left(\mathrm{t},{ }^{3} \mathrm{~J}=7.1 \mathrm{~Hz}, 3 \mathrm{H}\right)$.

${ }^{13}$ C-NMR $\left(\mathbf{C D C l}_{3}, \mathbf{7 5} \mathbf{M H z}\right): \delta(\mathrm{ppm})=164.7,149.5,141.0,137.5,130.8,129.2,128.4$, $126.9,125.8,124.1,62.3,14.2$.

IR (ATR): v ( $\left.\mathrm{cm}^{-1}\right)=3102$ (s), 2992 (s), 1724 (s), 1550 (vs), 1480 (s), 1454 (m), 1440 (m), 1338 (m), 1264 (s), 1238 (s), 1196 (m), 1146 (s), 1100 (s), 1028 (m), 894 (m), 798 (s), $774(\mathrm{~s}), 750(\mathrm{~s}), 662(\mathrm{~m}), 594(\mathrm{w})$.

MS (EI, 70 eV): $m / z(\%)=281(16), 280(96)\left[\mathrm{M}^{+},{ }^{79} \mathrm{Br}\right], 279(15), 278(100)\left[\mathrm{M}^{+},{ }^{81} \mathrm{Br}\right]$, 251 (11), 236 (29), 234 (29), 207 (23), 205 (22), 200 (40), 172 (29), 128 (35), 126 (42), 116 (12), 101 (19), 75 (12).

HR-MS: $\left(\mathrm{C}_{12} \mathrm{H}_{10} \mathrm{BrNO}_{2}\right) \quad$ calculated $278.9895 \quad$ found 278.9903

\section{Synthesis of 3-Benzyl-2-bromo-4-methylsulfanylquinoline (12)}

Prepared according to GP1 from 3-benzyl-2,4-dibromoquinoline (11j) (3.0 mmol, $1.13 \mathrm{~g}, 1.0$ equiv) dissolved in THF ( $3 \mathrm{~mL}), i \mathrm{PrMgCl} \cdot \mathrm{LiCl}(4)$ [reaction condition: $-50{ }^{\circ} \mathrm{C}$ for $12 \mathrm{~h}$ ], and 
benzenethiosulfonic acid $S$-methyl ester ${ }^{6}$ ( $3.6 \mathrm{mmol}, 675 \mathrm{mg}, 1.2$ equiv) [reaction condition: $-50{ }^{\circ} \mathrm{C}$ to $\mathrm{rt}$ for $12 \mathrm{~h}$ ]. The crude residue was purified by flash-chromatography $\left(\mathrm{SiO}_{2}\right.$, pentane/ether) yielding 3-benzyl-2-bromo-4-methylsulfanylquinoline (12) (897 mg, 87\%) as a colourless oil.

${ }^{1} \mathbf{H}-\mathrm{NMR}\left(\mathbf{C D C l}_{3}, \mathbf{3 0 0} \mathbf{M H z}\right): \delta(\mathrm{ppm})=8.51(\mathrm{~d}, J=8.4 \mathrm{~Hz}, 1 \mathrm{H}), 8.10(\mathrm{~d}, J=8.8 \mathrm{~Hz}, 1 \mathrm{H})$, 7.78-7.66 (m, 2H), 7.31-7.16 (m, 5H), $4.82(\mathrm{~s}, 2 \mathrm{H}), 2.28(\mathrm{~s}, 3 \mathrm{H})$.

${ }^{13} \mathbf{C}-\mathrm{NMR}\left(\mathbf{C D C l}_{3}, \mathbf{7 5} \mathbf{M H z}\right): \delta(\mathrm{ppm})=147.6,147.0,145.6,138.8,138.4,130.1,130.1$, 129.4, 129.4, 128.8, 128.4, 128.4, 127.9, 126.6, 126.2, 40.3, 20.0.

IR (ATR): $v\left(\mathrm{~cm}^{-1}\right)=3028(\mathrm{w}), 2924(\mathrm{vw}), 1708(\mathrm{vs}), 1476(\mathrm{~m}), 1356(\mathrm{~s}), 1220(\mathrm{~s}), 1136$ (m), 1028 (s), $916(\mathrm{~m}), 884(\mathrm{~m}), 764(\mathrm{~s}), 744(\mathrm{~m}), 724(\mathrm{~s}), 712(\mathrm{~m})$.

MS (EI, 70 eV): $m / z(\%)=345(100)\left[\mathrm{M}^{+},{ }^{81} \mathrm{Br}\right], 343(94)\left[\mathrm{M}^{+},{ }^{79} \mathrm{Br}\right], 329$ (5), 327 (6), 264 (31), 217 (24), 216 (88), 189 (5), 91 (4).

HR-MS: $\left(\mathrm{C}_{17} \mathrm{H}_{14} \mathrm{BrNS}\right)$

calculated 343.0030

found 343.0016

\section{Synthesis of 2-(3-benzyl-4-methylsulfanylquinolin-2-ylmethyl)-acrylic acid ethyl ester} (13)

A dry and argon flushed flask, equipped with a magnetic stirring bar and a septum, was charged with $\mathrm{Mes}_{2} \mathrm{Mg} \cdot \mathrm{LiBr}(6)$ (1.1 mmol, 1.1 equiv, $0.62 \mathrm{M}$ of $[\mathrm{Mg}]$ in THF) and TMEDA $\left(0.18 \mathrm{~mL}, 1.1 \mathrm{mmol}, 1.1\right.$ equiv) and stirred at $0{ }^{\circ} \mathrm{C}$ for $10 \mathrm{~min}$. Therefore, a solution of 3benzyl-2-bromo-4-methylsulfanyl-quinoline (12) $(1 \mathrm{mmol}, 344 \mathrm{mg}, 1.0$ equiv) dissolved in THF $(1 \mathrm{~mL})$ was added slowly, dropwise, at $0{ }^{\circ} \mathrm{C}$ and stirred for $12 \mathrm{~h}$. The completion of the $\mathrm{Br} / \mathrm{Mg}$ exchange was checked by GC-analysis using decane as internal standard. Ethyl (2bromomethyl)acrylate ${ }^{8}$ was then added to the mixture at $-20{ }^{\circ} \mathrm{C}$, followed by 2 drops of $\mathrm{CuCN} \cdot 2 \mathrm{LiCl}$ (cat., $1 \mathrm{M}$ in THF) and the reaction mixture was warmed to $\mathrm{rt}$ over $12 \mathrm{~h}$. Sat. $\mathrm{NH}_{4} \mathrm{Cl}$ solution was added and the mixture was extracted three times with EtOAc. The solvent was evaporated and the crude residue was purified by flash-chromatography $\left(\mathrm{SiO}_{2}\right.$, pentane/ether, 7:3) yielding 2-(3-benzyl-4-methylsulfanyl-quinolin-2-ylmethyl)-acrylic acid ethyl ester (13) (263 $\mathrm{mg}, 70 \%)$ as a colourless oil.

${ }^{1} \mathbf{H}-\mathrm{NMR}\left(\mathbf{C D C l}_{3}, \mathbf{6 0 0} \mathbf{M H z}\right): \delta(\mathrm{ppm})=8.52(\mathrm{~d}, J=8.1 \mathrm{~Hz}, 1 \mathrm{H}), 7.99(\mathrm{~d}, J=8.1 \mathrm{~Hz}, 1 \mathrm{H})$, 7.70-7.63 (m, 2H), 7.07-7.02 (m, 3H), 6.85-6.83(m, 2H), 6.25 (d, $J=1.8 \mathrm{~Hz}, 1 \mathrm{H}), 5.87$ (d, $J=$ $1.8 \mathrm{~Hz}, 1 \mathrm{H}), 4.19$ (q, $J=7.3 \mathrm{~Hz}, 2 \mathrm{H}), 4.03(\mathrm{~s}, 2 \mathrm{H}), 2.22(\mathrm{~s}, 3 \mathrm{H}), 1.28(\mathrm{t}, J=7.3 \mathrm{~Hz}, 3 \mathrm{H})$.

${ }^{13}$ C-NMR (CDCl 3,150 MHz): $\delta(\mathrm{ppm})=166.7,158.8,146.6,145.4,140.0,138.0,137.4$, $130.4,129.2,129.1,129.0,129.0,127.8,127.8,127.6,126.2,125.7,125.7,60.6,54.5,37.2$, 19.6, 14.2 .

IR (ATR): $v\left(\mathrm{~cm}^{-1}\right)=3060(\mathrm{w}), 2984(\mathrm{w}), 1716(\mathrm{vs}), 1636(\mathrm{~m}), 1604(\mathrm{w}), 1556(\mathrm{~m}), 1480$ (w), $1380(\mathrm{~m}), 1308(\mathrm{~m}), 1264(\mathrm{~m}), 1176(\mathrm{~m}), 1124(\mathrm{~m}), 976(\mathrm{w}), 952(\mathrm{w}), 820(\mathrm{w}), 746(\mathrm{~m})$.

MS (EI, 70 eV): $m / z(\%)=324$ (1), 308 (5), 254 (28), 240 (100), 193 (15), 68 (11).

HR-MS: $\left(\mathrm{C}_{23} \mathrm{H}_{23} \mathrm{NO}_{2}{ }^{32} \mathrm{~S}\right) \quad$ calculated $377.1449 \quad$ found 377.1444

\section{Synthesis of ethyl 2-bromo-4-pivaloylquinoline-3-carboxylate (15)}

Prepared according to GP2 and GP3 from 2-bromoquinoline-3-carboxylic acid ethyl ester (11k) $\left(2.0 \mathrm{mmol}, 560 \mathrm{mg}, 1.0\right.$ equiv), TMPMgCl$\cdot \mathrm{LiCl}(7)$ [reaction condition: $0{ }^{\circ} \mathrm{C}$ for $3 \mathrm{~h}$ ], $\mathrm{CuCN} \cdot 2 \mathrm{LiCl}$ [reaction condition: $-40{ }^{\circ} \mathrm{C}$ for $10 \mathrm{~min}$ ], and pivaloyl chloride $(2.2 \mathrm{mmol}, 240$ mg, 1.2 equiv) [reaction condition: $-40^{\circ} \mathrm{C}$ to $\mathrm{rt}$ for $6 \mathrm{~h}$ ]. The crude residue was purified by flash-chromatography $\left(\mathrm{SiO}_{2}\right.$, pentane/ether 7:3) yielding ethyl 2-bromo-4-pivaloylquinoline3-carboxylate (15) (612 $\mathrm{mg}, 84 \%)$ as a colourless solid.

mp.: $120.2-121.9^{\circ} \mathrm{C}$. 
${ }^{1} \mathbf{H}-\mathbf{N M R}\left(\mathbf{C D C l}_{3}, 300 \mathrm{MHz}\right): \delta(\mathrm{ppm})=8.08(\mathrm{~d}, J=8.4 \mathrm{~Hz}, 1 \mathrm{H}), 7.80(\mathrm{td}, J=6.2 \mathrm{~Hz}, J=$ $1.9 \mathrm{~Hz}, 1 \mathrm{H}), 7.64-7.55(\mathrm{~m}, 2 \mathrm{H}), 4.42(\mathrm{q}, J=7.1 \mathrm{~Hz}, 2 \mathrm{H}), 1.41(\mathrm{t}, J=7.1 \mathrm{~Hz}, 3 \mathrm{H}), 1.26(\mathrm{~s}$, 9H).

${ }^{13}$ C-NMR $\left(\mathbf{C D C l}_{3}, 75 \mathbf{M H z}\right): \delta(\mathrm{ppm})=211.4,165.6,149.3,148.2,137.7,132.1,129.3$, 128.2, 126.1, 124.3, 122.4, 62.9, 45.3, 27.7, 27.7, 27.7, 13.9.

IR (ATR): $v\left(\mathrm{~cm}^{-1}\right)=2976(\mathrm{w}), 1725(\mathrm{vs}), 1691(\mathrm{~s}), 1558(\mathrm{~m}), 1267(\mathrm{~m}), 1231$ (s), 1182 (s), $1152(\mathrm{~m}), 1086(\mathrm{~m}), 1012(\mathrm{~m}), 977(\mathrm{~m}), 771(\mathrm{~s}), 756(\mathrm{~m})$.

MS (EI, 70 eV): $m / z(\%)=320$ (4), 318 (4), 309 (40), 308 (29), 307 (41), 280 (98), 278 (100), 208 (9), 198 (12), 154 (22), 126 (8), 57 (7).

HR-MS: $\left(\mathrm{C}_{17} \mathrm{H}_{18} \mathrm{BrNO}_{4}\right) \quad$ calculated $[\mathrm{M}-\mathrm{H}]^{+} 364.0549 \quad$ found 364.0540

\section{Synthesis of ethyl 2-bromo-3-pivaloylquinoline-4-carboxylate (16)}

Prepared according to GP2 and GP3 from ethyl 2-bromoquinoline-4-carboxylate (111) (5.7 mmol, $1.59 \mathrm{~g}, 1.0$ equiv) dissolved in dry THF $(5 \mathrm{~mL}), \mathrm{TMPMgCl} \cdot \mathrm{LiCl}$ (7) [reaction condition: $-20^{\circ} \mathrm{C}$ for $3 \mathrm{~h}$ ], $\mathrm{CuCN} \cdot 2 \mathrm{LiCl}$ [reaction condition: $-40^{\circ} \mathrm{C}$ for $30 \mathrm{~min}$ ], and pivaloyl chloride (6.8 mmol, $748 \mathrm{mg}, 1.2$ equiv) [reaction condition: $-40^{\circ} \mathrm{C}$ warmed to $\mathrm{rt}$ for $12 \mathrm{~h}$ ]. The crude residue was purified by flash-chromatography $\left(\mathrm{SiO}_{2}\right.$, pentane/ether 8:2) yielding ethyl 2-bromo-3-pivaloylquinoline-4-carboxylate (16) $(1.67 \mathrm{~g}, 81 \%)$ as a colourless crystalline solid.

mp.: $70.8-72.0^{\circ} \mathrm{C}$.

${ }^{1} \mathbf{H}-\mathbf{N M R}\left(\mathbf{C D C l}_{3}, 300 \mathrm{MHz}\right): \delta(\mathrm{ppm})=8.08\left(\mathrm{~d},{ }^{3} \mathrm{~J}=8.4 \mathrm{~Hz}, 1 \mathrm{H}\right), 7.98\left(\mathrm{~d},{ }^{3} J=8.4 \mathrm{~Hz}, 1 \mathrm{H}\right)$, $7.80\left(\mathrm{t},{ }^{3} J=7.1 \mathrm{~Hz}, 1 \mathrm{H}\right), 7.65\left(\mathrm{t},{ }^{3} J=7.1 \mathrm{~Hz}, 1 \mathrm{H}\right), 4.46\left(\mathrm{q},{ }^{3} J=7.1 \mathrm{~Hz}, 2 \mathrm{H}\right), 1.41\left(\mathrm{t},{ }^{3} J=\right.$ $7.1 \mathrm{~Hz}, 3 \mathrm{H}), 1.33(\mathrm{~s}, 9 \mathrm{H})$.

${ }^{13} \mathbf{C}-\mathrm{NMR}\left(\mathbf{C D C l}_{3}, 75 \mathbf{M H z}\right): \delta(\mathrm{ppm})=210.0,165.4,147.9,137.0,136.2,134.6,131.4$, $129.0,128.7,125.5,122.6,63.0,45.4,28.2,28.2,28.2,14.0$.

IR (ATR): $v\left(\mathrm{~cm}^{-1}\right)=2976(\mathrm{~m}), 1724(\mathrm{vs}), 1690(\mathrm{~s}), 1552(\mathrm{~s}), 1482(\mathrm{~m}), 1456(\mathrm{~m}), 1270(\mathrm{~m})$, 1220 (vs), 1186 (m), 1142 (m), 1078 (s), 1014 (m), 978 (m), 890 (m), 762 (s), 682 (w), $580(\mathrm{w})$.

MS (EI, $70 \mathbf{~ e V ) : ~} m / z(\%)=364\left[\mathrm{M}^{+}\right]$not found, 308 (37), 307 (16), 306 (47), 305 (11), 280 (13), 279 (98), 278 (14), 277 (100), 153 (18).

HR-MS: $\left(\mathrm{C}_{17} \mathrm{H}_{18} \mathrm{BrNO}_{3}\right) \quad$ calculated $[\mathrm{M}-\mathrm{H}]^{+} 364.0549 \quad$ found 364.0573

\section{Synthesis of 2-bromo-3-pivaloyl-8-(4-ethoxycarbonyl-phenyl)-quinoline-4-carboxylic acid ethyl ester (17)}

A dry and argon flushed flask, equipped with a magnetic stirring bar and a septum, was charged with ethyl 2-bromo-3-pivaloylquinoline-4-carboxylate (16) (1 mmol, $365 \mathrm{mg}, 1.0$ equiv) dissolved in dry THF $(1 \mathrm{~mL}) . \mathrm{TMP}_{2} \mathrm{Mg} \cdot 2 \mathrm{LiCl}(\mathbf{8})$ was added dropwise to the mixture at $0{ }^{\circ} \mathrm{C}$ and the resulting mixture was stirred at this temperature for $20 \mathrm{~h}$. The completion of the $\mathrm{Br} / \mathrm{Mg}$ exchange was checked by TLC. The freshly prepared magnesium reagent was then transmetalated with $\mathrm{ZnCl}_{2}\left(1.1 \mathrm{~mL}, 1.1\right.$ equiv, $1 \mathrm{M}$ in dry THF) at $0{ }^{\circ} \mathrm{C}$ and the mixture was warmed to $\mathrm{rt}$ for $1 \mathrm{~h}$. 4-Iodo-benzoic acid ethyl ester $(358 \mathrm{mg}, 1.3 \mathrm{mmol}, 1.3$ equiv) was added to the reaction mixture at rt. A flame-dried round bottom flask was charged with $\mathrm{Pd}(\mathrm{dba})_{2}(30 \mathrm{mg}, 5 \mathrm{~mol} \%), \mathrm{P}(o \text {-furyl })_{3}(24 \mathrm{mg}, 10 \mathrm{~mol} \%)$ and THF $(1 \mathrm{~mL})$. The mixture was stirred at $25{ }^{\circ} \mathrm{C}$ for $10 \mathrm{~min}$ then transferred to the reaction flask which was charged with the organozinc solution. The resulting mixture was stirred and refluxed for $4 \mathrm{~h}$, quenched with sat. aq. $\mathrm{NH}_{4} \mathrm{Cl}$ and extracted three times with AcOEt. The solvent was evaporated and the product was purified by flash-chromatography $\left(\mathrm{SiO}_{2}\right.$, pentane/ether 7:3) yielding 2-bromo-3(2,2-dimethyl-propionyl)-8-(4-ethoxycarbonyl-phenyl)-quinoline-4-carboxylic acid ethyl ester 
(17) (363 mg, 71\%) as a colourless solid.

mp.: 126.0 - $129.1^{\circ} \mathrm{C}$.

${ }^{1}$ H-NMR $\left(\mathbf{C D C l}_{3}, \mathbf{6 0 0} \mathbf{M H z}\right): \delta(\mathrm{ppm})=8.16\left(\mathrm{~d},{ }^{3} J=8.3 \mathrm{~Hz}, 2 \mathrm{H}\right), 7.98\left(\mathrm{~d},{ }^{3} J=8.3 \mathrm{~Hz}, 1 \mathrm{H}\right)$, $7.85\left(\mathrm{~d},{ }^{3} J=7.3 \mathrm{~Hz}, 1 \mathrm{H}\right), 7.76-7.71(\mathrm{~m}, 3 \mathrm{H}), 4.48\left(\mathrm{q},{ }^{3} J=7.2 \mathrm{~Hz}, 2 \mathrm{H}\right), 4.42\left(\mathrm{q},{ }^{3} J=7.2 \mathrm{~Hz}\right.$, $2 \mathrm{H}), 1.45-1.41(\mathrm{~m}, 6 \mathrm{H}), 1.33(\mathrm{~s}, 9 \mathrm{H})$.

${ }^{13}$ C-NMR $\left(\mathbf{C D C l}_{3}, 150 \mathrm{MHz}\right): \delta(\mathrm{ppm})=210.1,166.6,165.5,145.2,142.4,139.3,137.4$, 135.8, 134.7, 132.0, 130.7 (2C), 129.7, 129.2 (2C), 128.4, 125.5, 123.1, 63.1, 61.0, 45.3, 28.2 (3C), 14.4, 14.0.

IR (ATR): $v\left(\mathrm{~cm}^{-1}\right)=2968(\mathrm{w}), 2908(\mathrm{w}), 1732(\mathrm{~s}), 1718(\mathrm{vs}), 1556(\mathrm{~s}), 1478(\mathrm{~m}), 1459(\mathrm{~m})$, 1364 (m), 1275 (s), 1235 (vs), 1177 (s), 1082 (s), 991 (s), 894 (m), 767 (vs), 699 (m).

HR-MS (FIA/ESI, LTQ/FT): $\left(\mathrm{C}_{26} \mathrm{H}_{26} \mathrm{BrNO}_{5}\right)$

calculated $[\mathrm{M}-\mathrm{H}]^{+} 512.1070 \quad$ found 512.1062

\section{Synthesis of 2-ethoxy-4,4,5,5-tetramethyl-[1,3,2]dioxaborolane (ethyl pinacol borate).}

Boric acid (1.24 g, 20mmol, 1 equiv), dry ethanol (4.40 g, $95.4 \mathrm{mmol}, 4.77$ equiv), and pinacol (2.36 g, 20mmol, 1 equiv) were mixed in $15 \mathrm{~mL}$ of dry benzene. After stirring $30 \mathrm{~min}$ at room temperature, the ethanol/water/benzene ternary azeotrope was distilled off for $10 \mathrm{~h}$, and most of the residual benzene was removed in vacuo at $30^{\circ} \mathrm{C}$. The crude product was distilled $\left(32{ }^{\circ} \mathrm{C}, 7\right.$ mbar) to give the title compound as a colourless liquid (V=1.5 mL, 41\%) containing no traces of benzene.

${ }^{1} \mathbf{H}-\mathrm{NMR}\left(\mathbf{C D C l}_{3}, \mathbf{2 0 0 M H z}\right): \delta(\mathrm{ppm})=3.84(\mathrm{q}, J=7.1 \mathrm{~Hz}, 2 \mathrm{H}), 1.20(\mathrm{~s}, 12 \mathrm{H}$ and $\mathrm{t}$ "overlapped", $3 \mathrm{H})$.

\section{Synthesis of 2-bromo-3-(4,4,5,5-tetramethyl-[1,3,2]dioxaborolan-2-yl)-quinoline-4- carboxylic acid ethyl ester (18).}

According to GP2 from ethyl 2-bromoquinoline-4-carboxylate (11l) $(5.0 \mathrm{mmol}, 1.39 \mathrm{~g}, 1.0$ equiv) dissolved in dry THF $(5 \mathrm{~mL}), \mathrm{TMPMgCl} \cdot \mathrm{LiCl}(7)$ [reaction condition: $-20{ }^{\circ} \mathrm{C}$ for $3 \mathrm{~h}$ ]. To the corresponding obtained 2-bromo-3-magnesiated-4-carboethoxyquinoline was added at $-50{ }^{\circ} \mathrm{C}$ freshly prepared ethyl pinacol borate $(1.03 \mathrm{~g}, 6 \mathrm{mmol}, 1.2 \mathrm{equiv})$ and the resulting mixture was stirred and warmed to rt for $12 \mathrm{~h}$. The reaction mixture was cooled to $-50{ }^{\circ} \mathrm{C}$ after which anhydrous $\mathrm{HCl}\left(3 \mathrm{~mL}, 6 \mathrm{mmol}, 1.2\right.$ equiv, $2 \mathrm{M}$ in $\left.\mathrm{Et}_{2} \mathrm{O}\right)$ was added. The cooling bath was removed and the reaction mixture was allowed to warm to rt. After removal of the precipitated $\mathrm{MgCl}$ by filtration and removal of the volatiles under reduced pressure, the crude residue was purified by flash-chromatography $\left(\mathrm{SiO}_{2}\right.$, pentane/ether 9:1) yielding 2-bromo-3(4,4,5,5-tetramethyl-[1,3,2]dioxaborolan-2-yl)-quinoline-4-carboxylic acid ethyl ester (18) $(1.44 \mathrm{~g}, 71 \%)$ as a colourless solid.

mp.: 85.9-88. $6^{\circ} \mathrm{C}$.

${ }^{1}$ H-NMR (CDCl 3 , 600 MHz): $\delta(\mathrm{ppm})=8.30\left(\mathrm{~d},{ }^{3} J=7.3 \mathrm{~Hz}, 1 \mathrm{H}\right), 8.05\left(\mathrm{~d},{ }^{3} J=7.3 \mathrm{~Hz}, 1 \mathrm{H}\right)$, $7.74\left(\mathrm{t},{ }^{3} J=7.0 \mathrm{~Hz}, 1 \mathrm{H}\right), 4.55\left(\mathrm{q},{ }^{3} J=7.3 \mathrm{~Hz}, 2 \mathrm{H}\right), 1.48\left(\mathrm{t},{ }^{3} J=7.1 \mathrm{~Hz}, 3 \mathrm{H}\right), 1.45(\mathrm{~s}, 12 \mathrm{H})$.

${ }^{13}$ C-NMR (CDCl 3 , 150 MHz): $\delta(\mathrm{ppm})=167.9,149.3,144.0,143.7,131.0,129.1,128.0$, 125.6, 122.9, 85.0 (2C), 62.8, 25.1 (4C), 14.3. [C from C-B bond, not visible].

IR (ATR): $v\left(\mathrm{~cm}^{-1}\right)=2996(\mathrm{w}), 2976(\mathrm{w}), 1692(\mathrm{~m}), 1552(\mathrm{~m}), 1368(\mathrm{~m}), 1312(\mathrm{~m}), 1291(\mathrm{~s})$, 1235 (s), 1140 (s), 1119 (s), $1016(\mathrm{~m}), 850$ (m), 771 (s).

MS (EI, 70 eV): $m / z(\%)=390$ (13), 347 (67), 317 (100), 277 (69), 233 (21), 154 (25), 127 (21), 43 (32).

HR-MS: $\left(\mathrm{C}_{18} \mathrm{H}_{21} \mathrm{~B}^{79} \mathrm{BrNO}_{4}\right) \quad$ calculated $405.0747 \quad$ found 405.0746 
Synthesis of 2-phenyl-3-(4,4,5,5-tetramethyl-[1,3,2]dioxaborolan-2-yl)-quinoline-4carboxylic acid ethyl ester (19)

To a solution of commercially available phenyl magnesium chloride in THF $(1.51 \mathrm{~mL}, 2.2$ mmol, $1.45 \mathrm{M}$ in THF) at $0{ }^{\circ} \mathrm{C}$ was added dropwise $\mathrm{ZnCl}_{2}(2.1 \mathrm{~mL}, 2.2 \mathrm{mmol}, 1.1$ equiv, 1.0 $\mathrm{M}$ in THF). After $30 \mathrm{~min}$ of stirring, a solution of the boronic ester $18(812 \mathrm{mg}, 2 \mathrm{mmol}, 1.0$ equiv) in dry THF $(1 \mathrm{~mL})$ was added dropwise, followed by the addition of $5 \mathrm{~mol} \%$ of $\mathrm{Pd}\left(\mathrm{Ph}_{3}\right)_{4}$. The resulting mixture was stirred at room temperature for $1 \mathrm{~h}$ and then quenched with sat. aq. $\mathrm{NH}_{4} \mathrm{Cl}$ and extracted three times with AcOEt. The solvent was evaporated and the product was purified by flash-chromatography $\left(\mathrm{SiO}_{2}\right.$, pentane/ether 7:3) yielding 2phenyl-3-(4,4,5,5-tetramethyl-[1,3,2]dioxaborolan-2-yl)-quinoline-4-carboxylic acid ethyl ester (19) (612 $\mathrm{mg}, 76 \%)$ as a colourless solid.

mp.: $237.5-239.9{ }^{\circ} \mathrm{C}$.

${ }^{1} \mathbf{H}-\mathbf{N M R}\left(\mathbf{C D C l}_{3}, \mathbf{3 0 0} \mathbf{M H z}\right): \delta(\mathrm{ppm})=8.27\left(\mathrm{~d},{ }^{3} J=7.9 \mathrm{~Hz}, 1 \mathrm{H}\right), 8.20\left(\mathrm{~d},{ }^{3} J=8.1 \mathrm{~Hz}, 1 \mathrm{H}\right)$, 7.78-7.69 (m, 3H), $7.59\left(\mathrm{t},{ }^{3} J=8.1 \mathrm{~Hz}, 1 \mathrm{H}\right), 7.48-7.42(\mathrm{~m}, 3 \mathrm{H}), 4.58\left(\mathrm{q},{ }^{3} J=7.1 \mathrm{~Hz}, 2 \mathrm{H}\right)$, $1.51\left(\mathrm{t},{ }^{3} \mathrm{~J}=8.1 \mathrm{~Hz}, 3 \mathrm{H}\right), 1.18(\mathrm{~s}, 12 \mathrm{H})$.

${ }^{13}$ C-NMR (CDCl $\left.3,75 \mathbf{M H z}\right): \delta(\mathrm{ppm})=168.9,162.2,148.4,143.2,142.1,130.2,130.1$, 129.3 (2C), 128.6, 128.1 (2C), 127.4, 125.0, 122.4, 84.4 (2C), 62.4, 25.0 (4C), 14.4. [C from C-B bond, not visible].

IR (ATR): v $\left(\mathrm{cm}^{-1}\right)=2981(\mathrm{~m}), 2928(\mathrm{w}), 1694(\mathrm{vs}), 1665(\mathrm{~m}), 1560(\mathrm{~m}), 1373$ (s), 1323 (vs), 1252 (m), 1220 (m), 1139 (vs), 1096 (vs), 1039 (m), 854 (w), 773 (m), 702 (m).

HR-MS (FIA/ESI, LTQ/FT): $\left(\mathrm{C}_{24} \mathrm{H}_{26} \mathrm{BNO}_{4}\right)$

calculated $[\mathrm{M}-\mathrm{H}]^{+} 404.2034 \quad$ found:404.2025

\section{Synthesis of 3-hydroxy-2-phenyl-quinoline-4-carboxylic acid (20)}

To a heterogeneous solution of 2-phenyl-3-(4,4,5,5-tetramethyl-[1,3,2]dioxaborolan-2-yl)quinoline-4-carboxylic acid ethyl ester (19) $(806 \mathrm{mg}, 1.2 \mathrm{mmol}$, 1. equiv) in $\mathrm{MeOH}(2 \mathrm{~mL})$ at rt, was added neat $\mathrm{LiOH}$ (172 mg, 6 equiv) and aq. solution of $\mathrm{H}_{2} \mathrm{O}_{2}(0.45 \mathrm{~mL}, 3$ equiv, $32 \%$ in water). The resulting mixture became rapidly yellow and homogenous and was stirred at $\mathrm{rt}$ for $15 \mathrm{~h}$. A precipitate was obtained and was filtrated and dried over vacuum. The crude residue was purified by flash-chromatography $\left(\mathrm{SiO}_{2}, \quad \mathrm{EtOAc} / \mathrm{CH}_{3} \mathrm{CN} / \mathrm{MeOH} / \mathrm{H}_{2} \mathrm{O}\right.$, 7:1:0.25:0.25 with $0.5 \% \mathrm{NEt}_{3}$ ) giving the corresponding ammonium salt which was dissolved in $\mathrm{CH}_{3} \mathrm{CN} / \mathrm{H}_{2} \mathrm{O} 1: 1$ and then acidified with $\mathrm{HCl}$ conc. to obtain a $\mathrm{pH}$ of 2 . A precipitate was collected by filtration and dried over vacuum. A yellow fluffy solid is obtained $(\mathbf{2 0}, 283 \mathrm{mg}$, $89 \%$ ).

mp.: $183.0-185.9^{\circ} \mathrm{C}$.

${ }^{1}$ H-NMR (DMSO-d $\left.\mathbf{d}_{\mathbf{6}}, 400 \mathrm{MHz}\right): \delta(\mathrm{ppm})=8.76(\mathrm{~d}, J=7.8 \mathrm{~Hz}, 1 \mathrm{H}), 8.04-7.99(\mathrm{~m}, 1 \mathrm{H})$, 7.66-7.58 (m, 3H), 7.56-7.51 (m, 5H).

${ }^{13}$ C-NMR (DMSO-d 6 , 100 MHz): $\delta(\mathrm{ppm})=171.0,153.8,151.5,139.7,135.7,129.7$ (2C), $129.5,128.4,127.9(2 \mathrm{C}), 126.5,125.3,124.6(2 \mathrm{C}), 155.4$.

IR (ATR): $v\left(\mathrm{~cm}^{-1}\right)=3395$ (mbroad), $2923(\mathrm{w}), 2596$ (mbroad), $1632(\mathrm{~m}), 1527(\mathrm{~m}), 1500$ (m), 1400 (s), 1322 (s), 1241 (s), 1160 (m), 1027 (m), 877 (m), 755 (s), 696 (s).

MS (EI, 70 eV): $m / z(\%)=265\left[\mathrm{M}^{+}\right](50), 247$ (39), 218 (100), 190 (31), 165 (18), 105 (23), $76(15), 44(22)$.

HR-MS: $\left(\mathrm{C}_{16} \mathrm{H}_{11} \mathrm{NO}_{3}\right) \quad$ calculated $265.0739 \quad$ found 265.0729

Synthesis of 3-hydroxy-2-phenyl-quinoline-4-carboxylic acid (1-phenyl-propyl)-amide (talnetant, 2).

This compound was prepared following the literature procedure. ${ }^{9}$ 
A pale yellow solid is obtained (2, 84\%).

mp.: $125.1-126.2^{\circ} \mathrm{C}$

${ }^{1}$ H-NMR (DMSO-d 6 , 400 MHz): $\delta(\mathrm{ppm})=9.78(\mathrm{~s}, 1 \mathrm{H}), 9.12(\mathrm{~d}, J=8.2 \mathrm{~Hz}, 1 \mathrm{H}), 7.98-7.94$ $(\mathrm{m}, 3 \mathrm{H}), 7.69-7.43(\mathrm{~m}, 8 \mathrm{H}), 7.38-7.34(\mathrm{~m}, 2 \mathrm{H}), 7.28-7.25(\mathrm{~m}, 1 \mathrm{H}), 5.08-5.02(\mathrm{q}, J=7.0 \mathrm{~Hz}$, $1 \mathrm{H}), 1.87-1.74(\mathrm{~m}, 2 \mathrm{H}), 0.95(\mathrm{t}, J=7.3 \mathrm{~Hz}, 3 \mathrm{H})$.

${ }^{13}$ C-NMR (DMSO-d $\mathbf{6}, \mathbf{1 0 0 M H z ) : ~} \delta(\mathrm{ppm})=164.6,152.3,144.5,143.4,142.3,137.8,129.4$ (2C), 129.0, 128.7 (2C), 128.1 (2C), 127.9, 126.9, 126.7 (5C), 125.4, 123.6, 54.8, 29.2, 11.1.

IR (ATR): $v\left(\mathrm{~cm}^{-1}\right)=3266$ (wbroad), 3058 (wbroad), 2931 (w), 1646 (s), 1629 (s), 1532 (s), 1492 (m), 1312 (m), 1236 (m), 1198 (m), 1146 (m), 760 (s), 695 (s).

HR-MS (FIA/ESI, LTQ/FT): $\left(\mathrm{C}_{25} \mathrm{H}_{22} \mathrm{~N}_{2} \mathrm{O}_{2}\right)$

calculated $[\mathrm{M}-\mathrm{H}]^{+} 383.1760 \quad$ found 383.1756 


\section{Spectra :}

\section{2,3-dibromoquinoline (9a)}

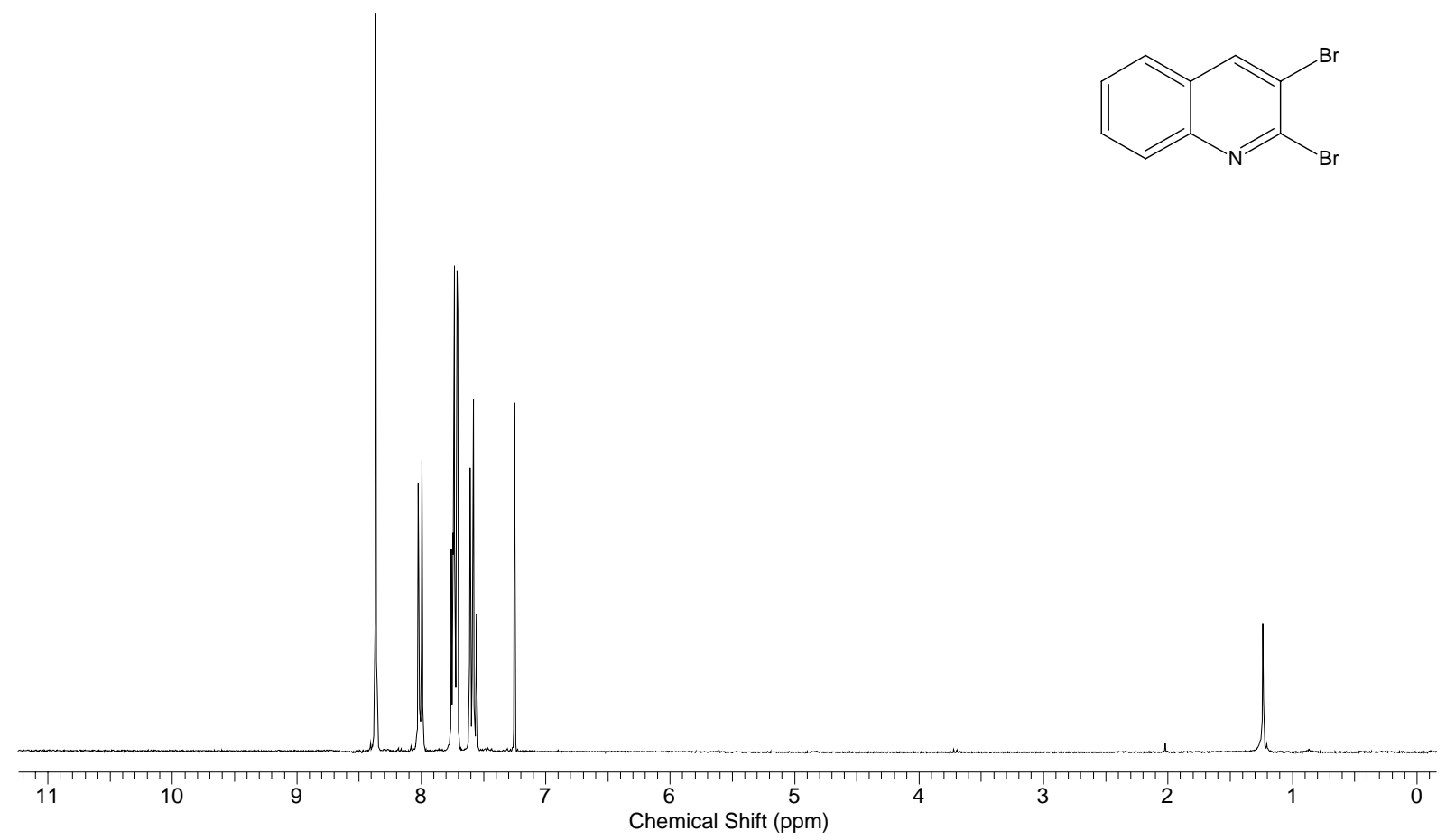

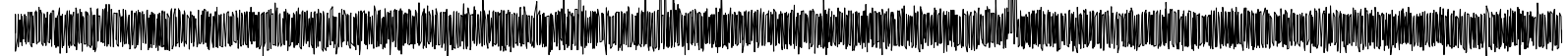

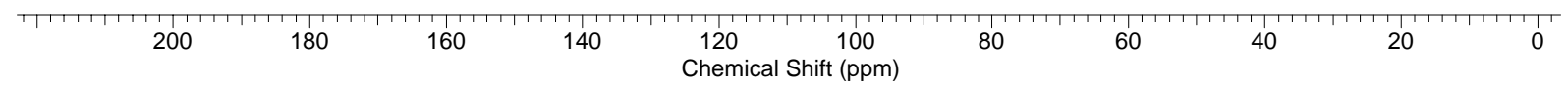




\section{2,4-dibromoquinoline (9b)}

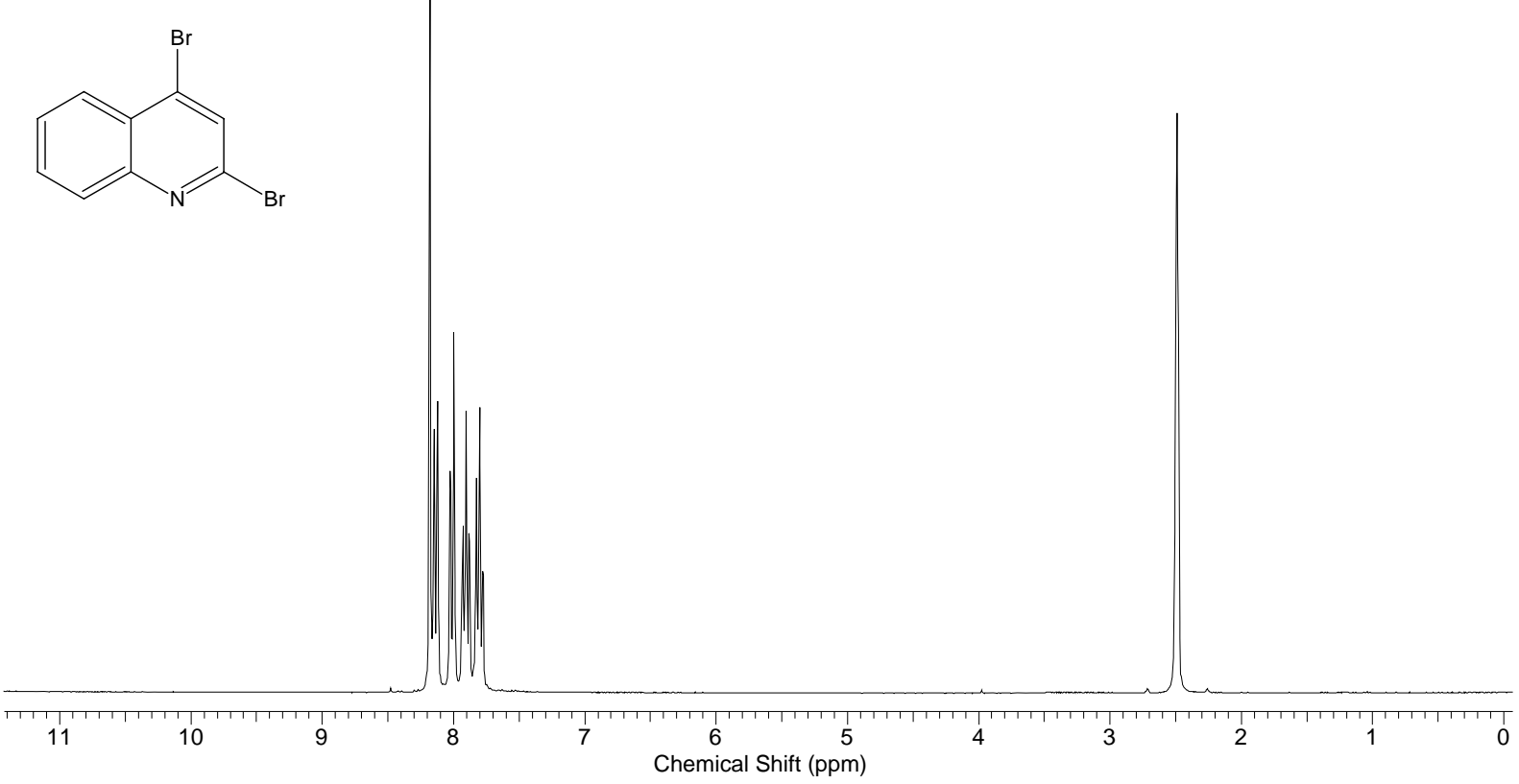<smiles>Brc1cc(Br)c2ccccc2n1</smiles>

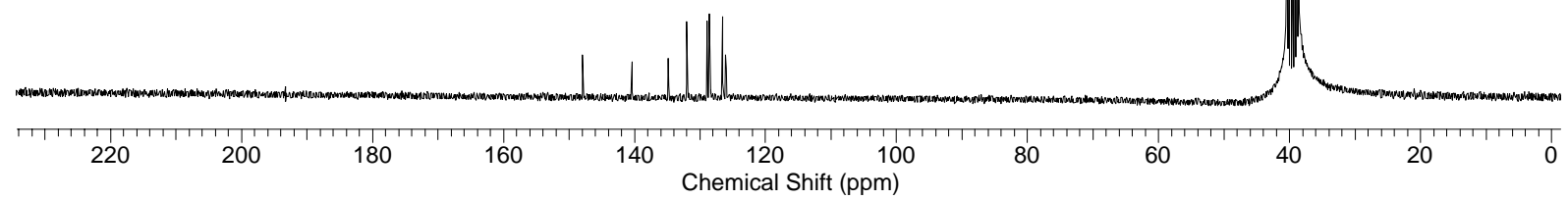


2,3,4 tribromoquinoline (9c)

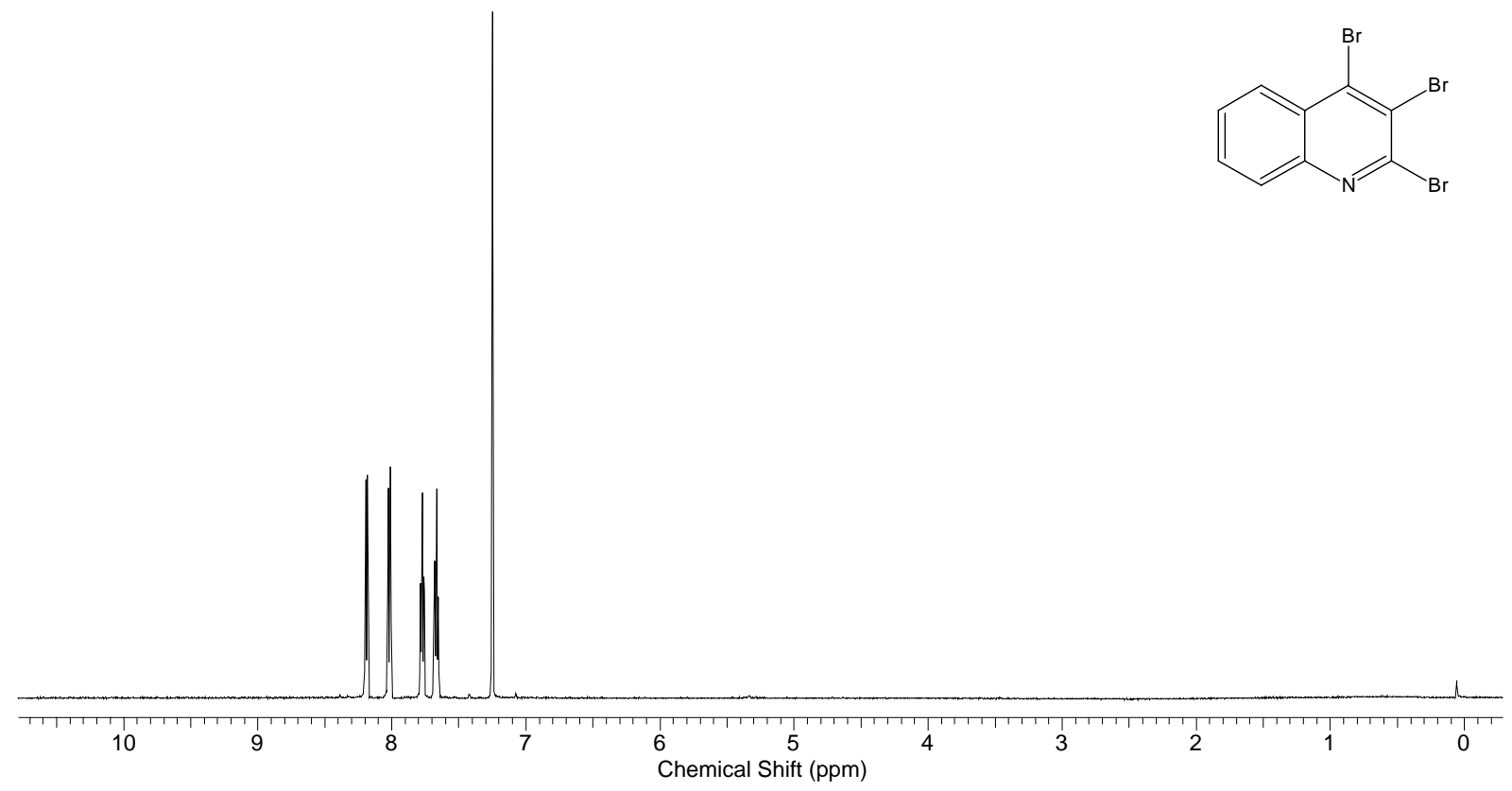<smiles>Brc1nc2ccccc2c(Br)c1Br</smiles>

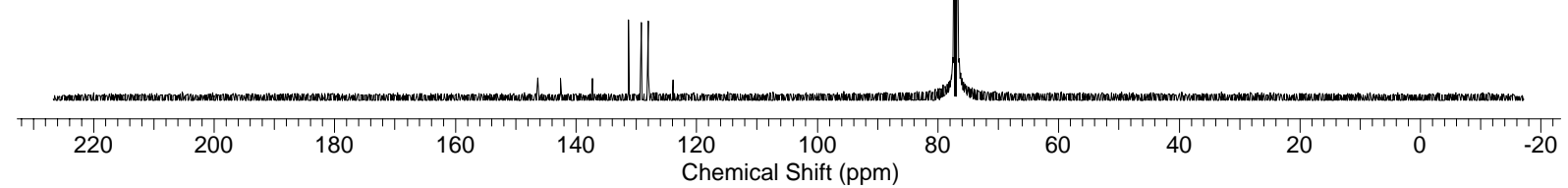


3-bromo-4-quinolinol

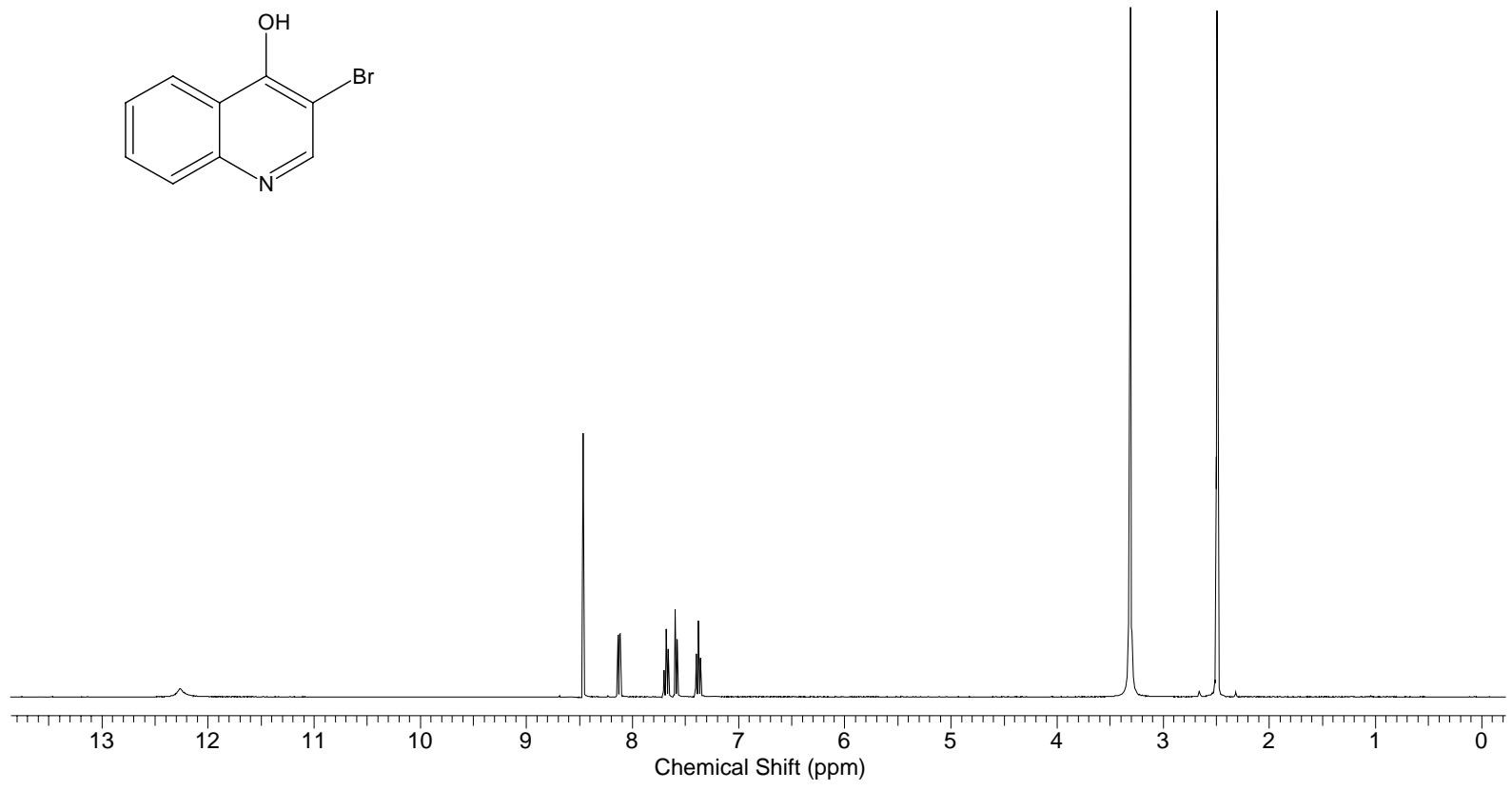<smiles>Oc1c(Br)cnc2ccccc12</smiles>

D.

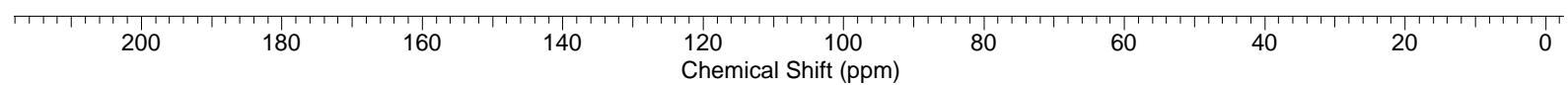


3, 4-dibromoquinoline (9d)
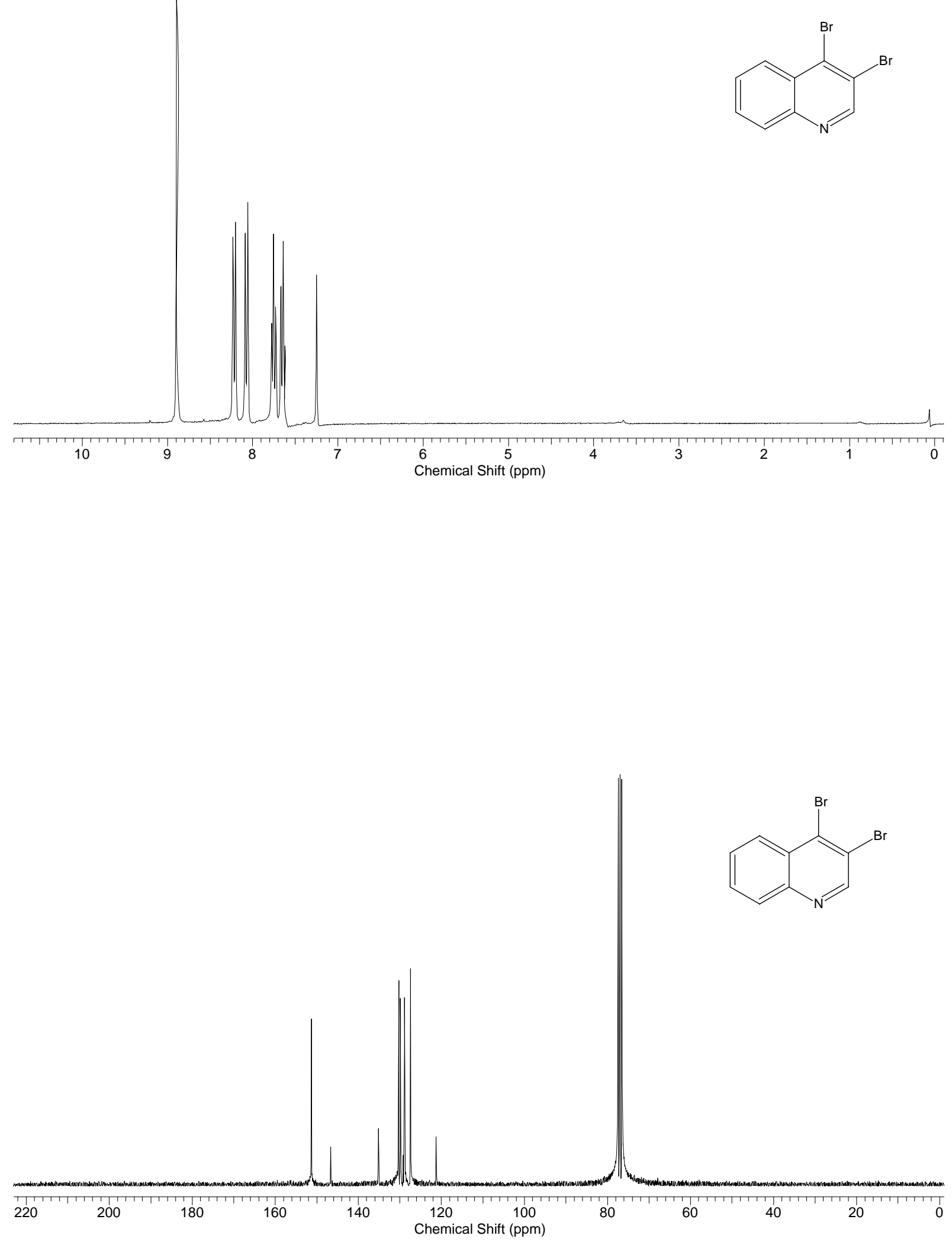
2-bromo-3-cyanoquinoline (11a)
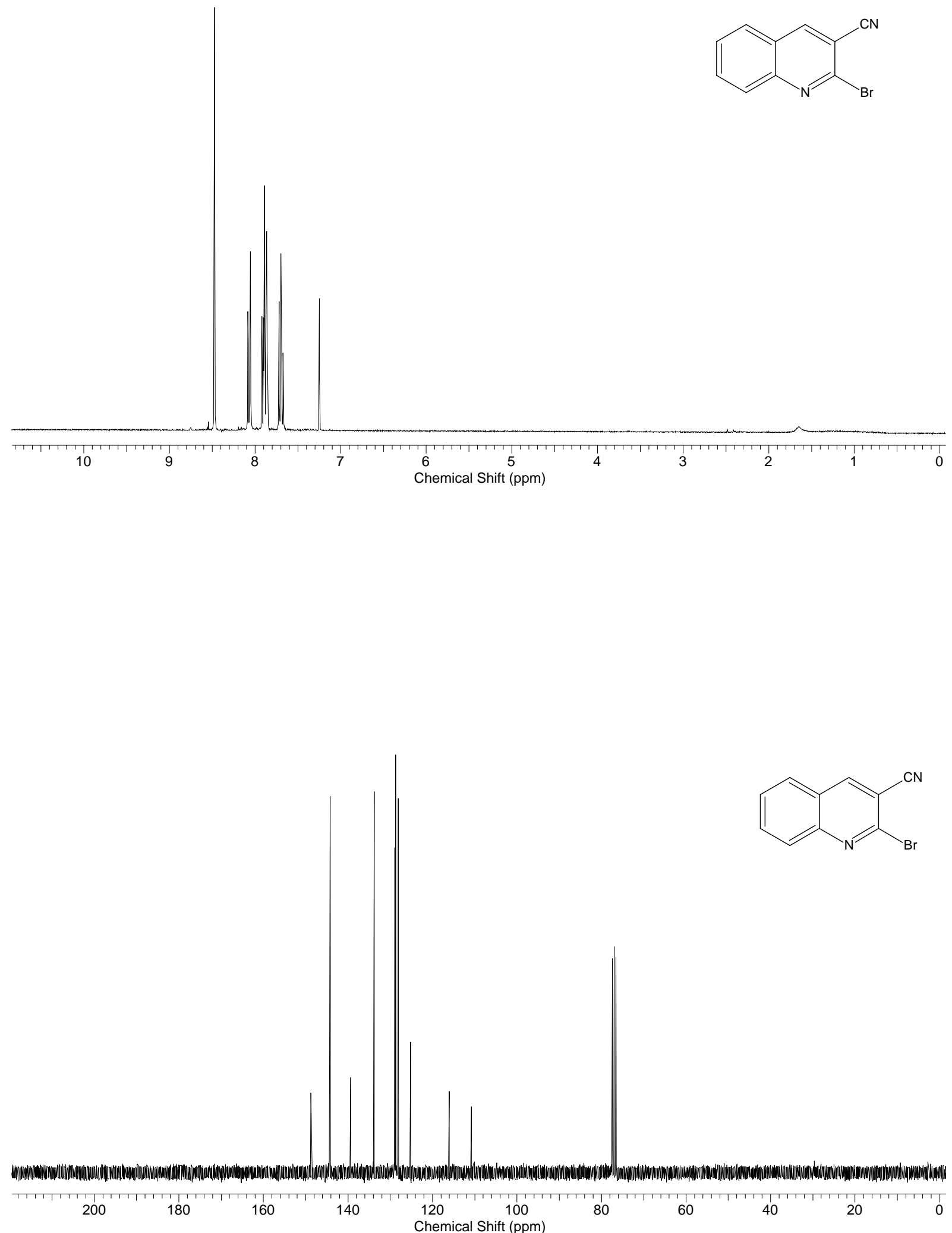
1-(2-Bromo-quinolin-3-yl)-propan-1-ol (11b)<smiles>CCC(O)c1cc2ccccc2nc1Br</smiles>

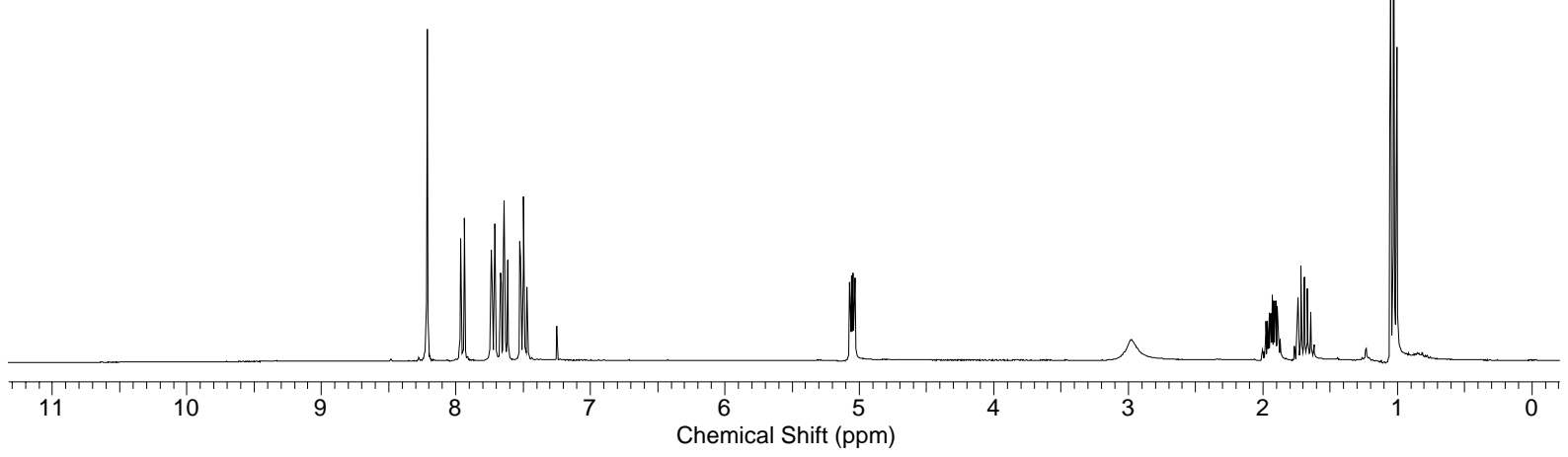<smiles>CCC(O)c1cc2ccccc2nc1Br</smiles>

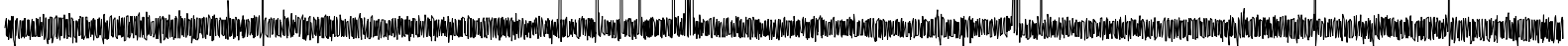

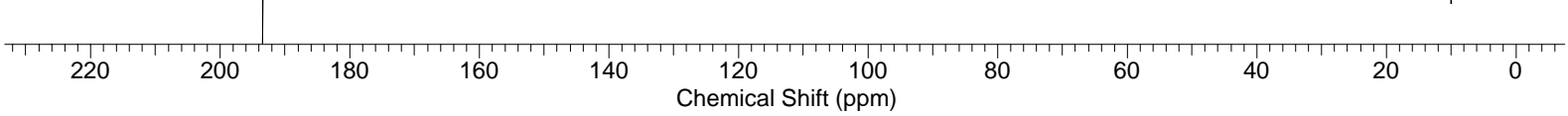


2-Bromo-4-phenylsulfanyl-quinoline (11c)
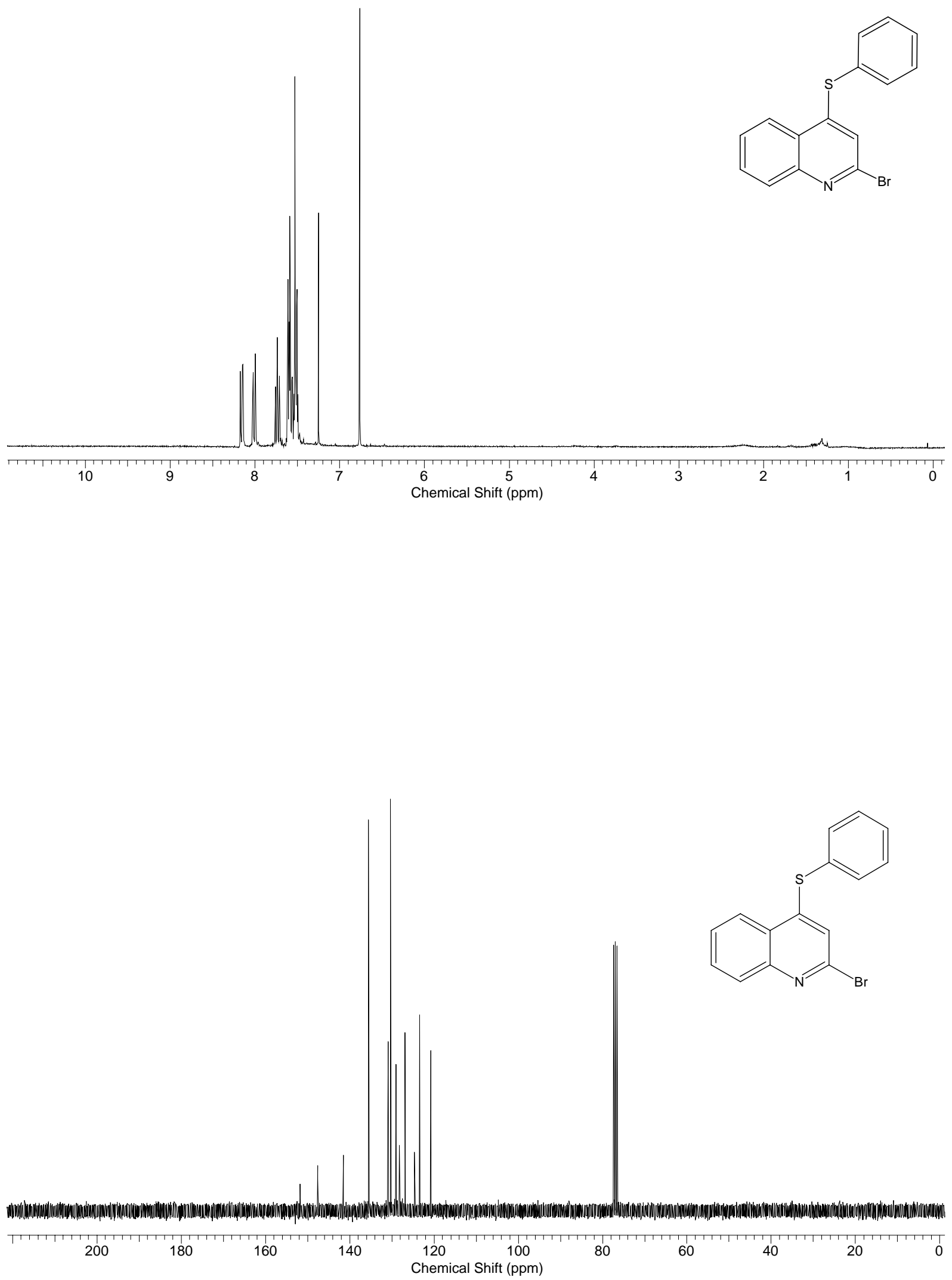
2-bromo-quinoline-4-carbonitrile (11d)
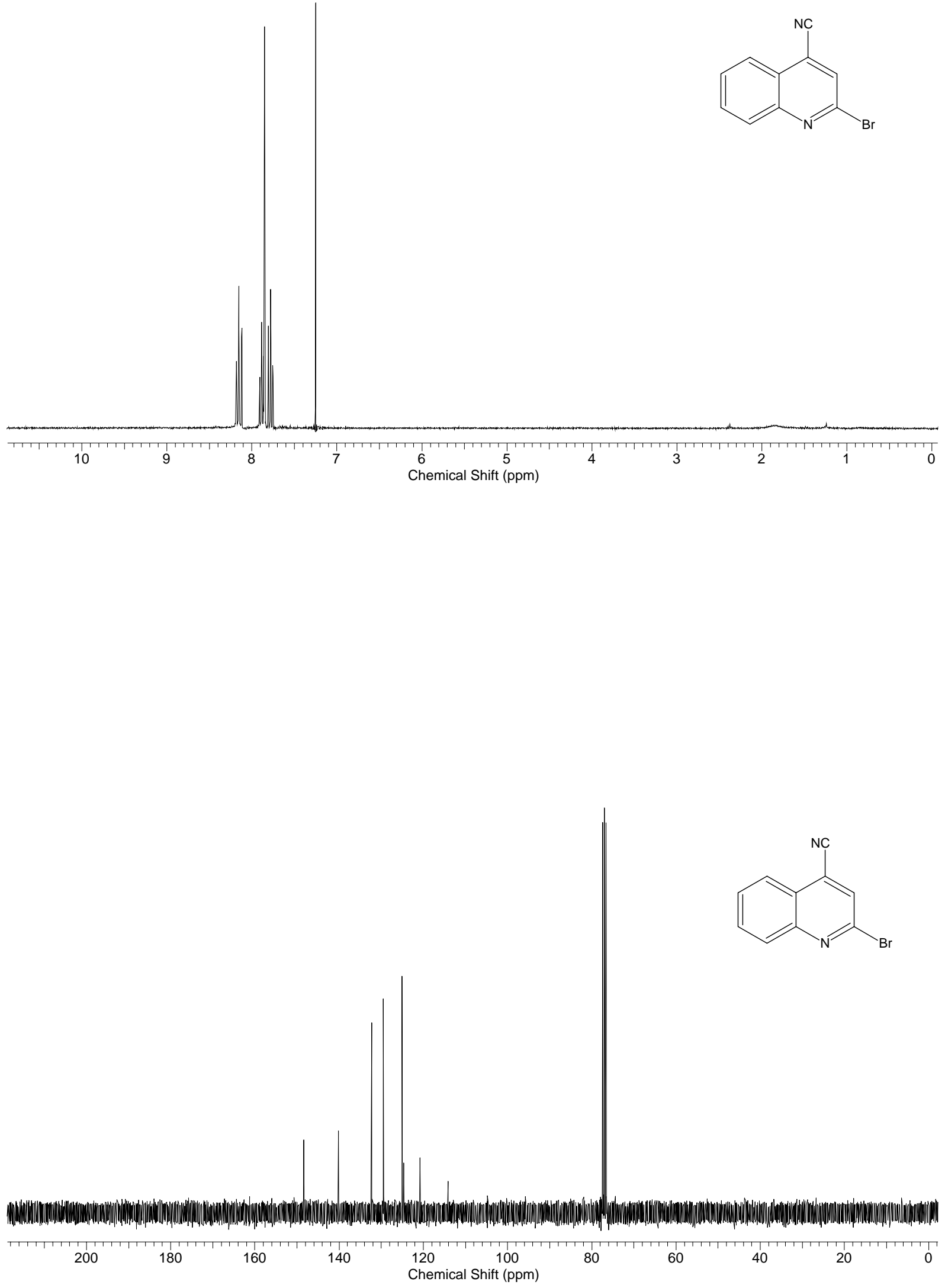
2-bromo-quinolin-4-ylamine (11e)<smiles>Nc1cc(Br)nc2ccccc12</smiles>
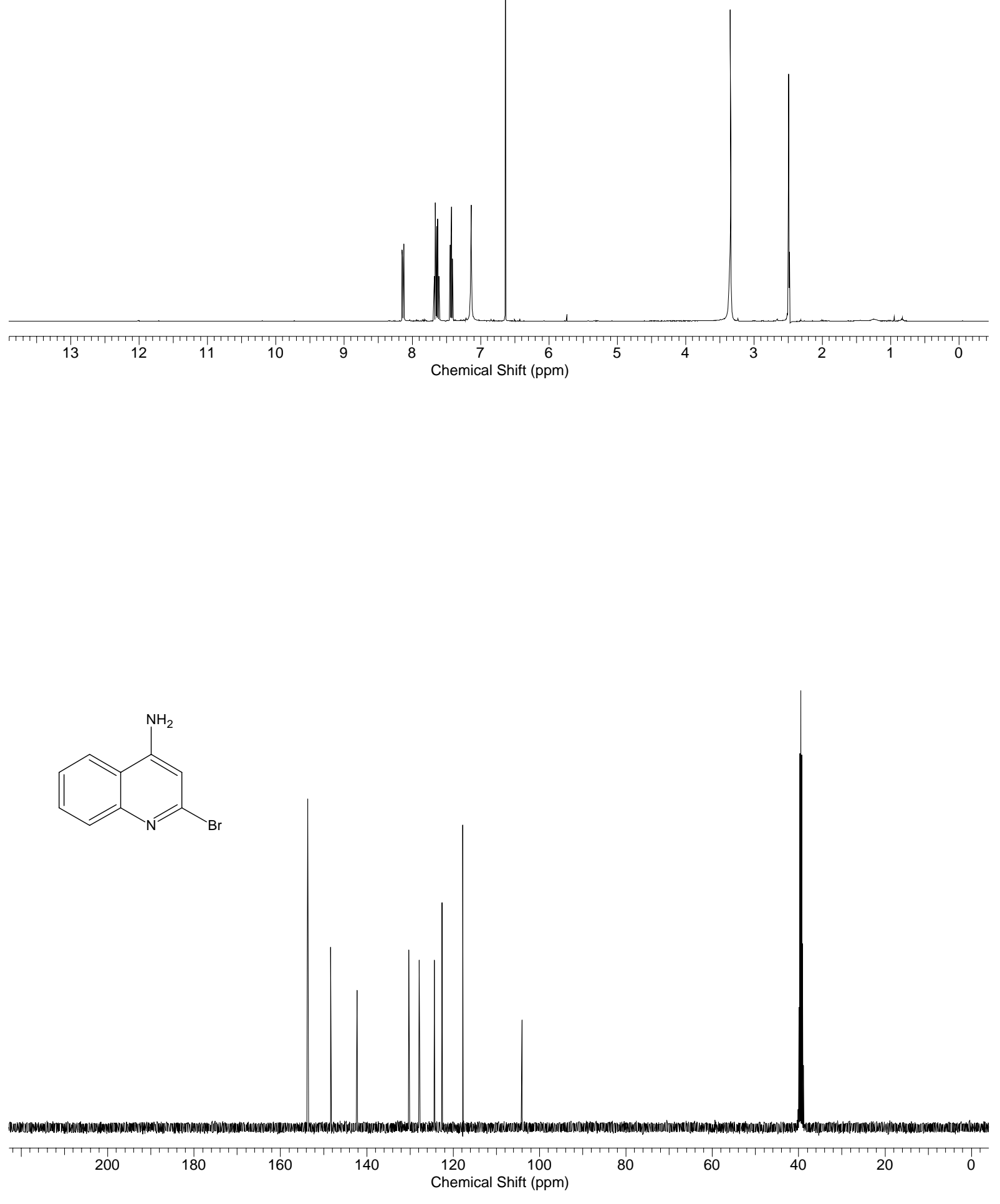
2,4-dibromo-quinoline-3-carbonitrile (11f)
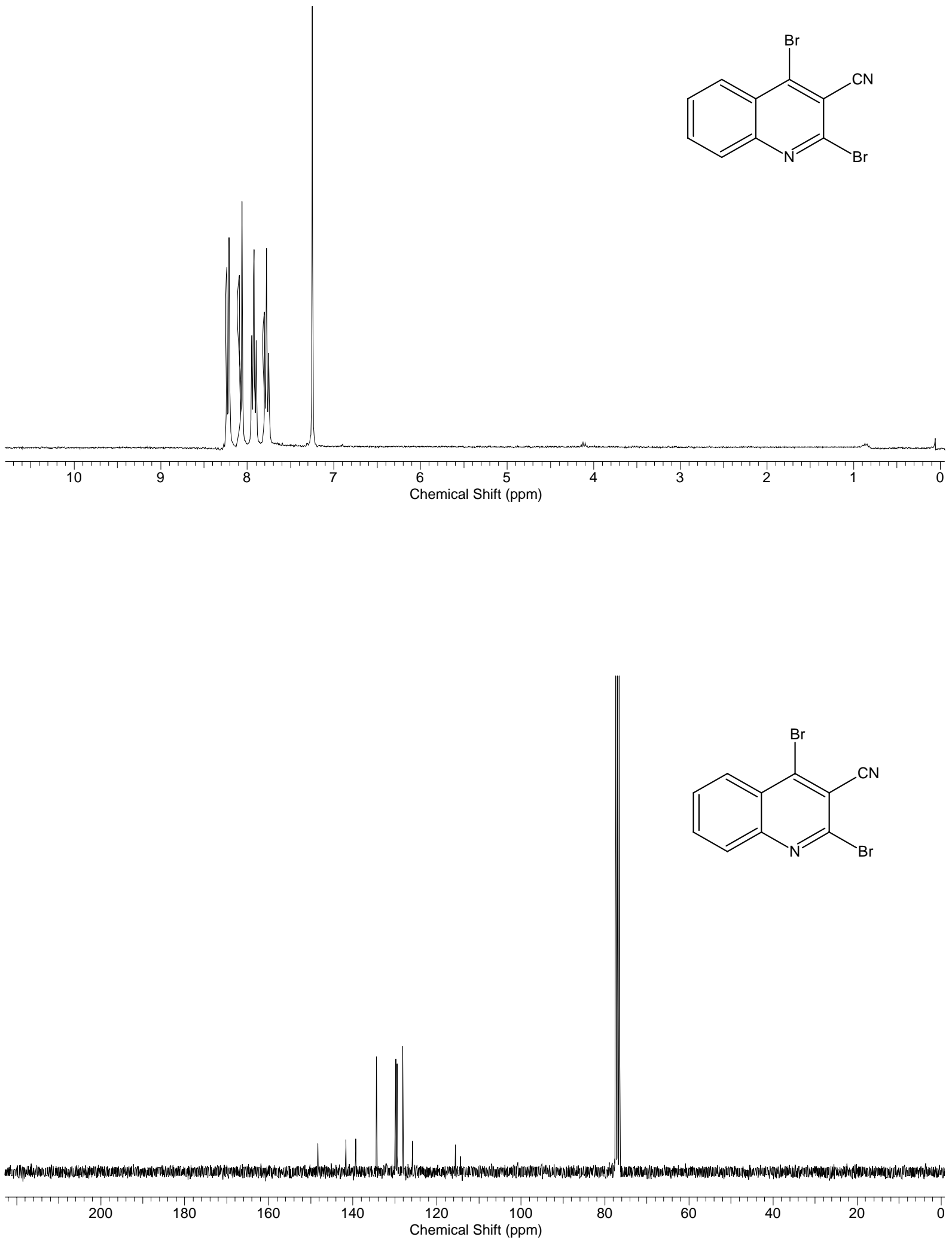
2,4-dibromo-quinoline-3-carboxylic acid ethyl ester (11g)<smiles>CCOC(=O)c1c(Br)nc2ccccc2c1Br</smiles>

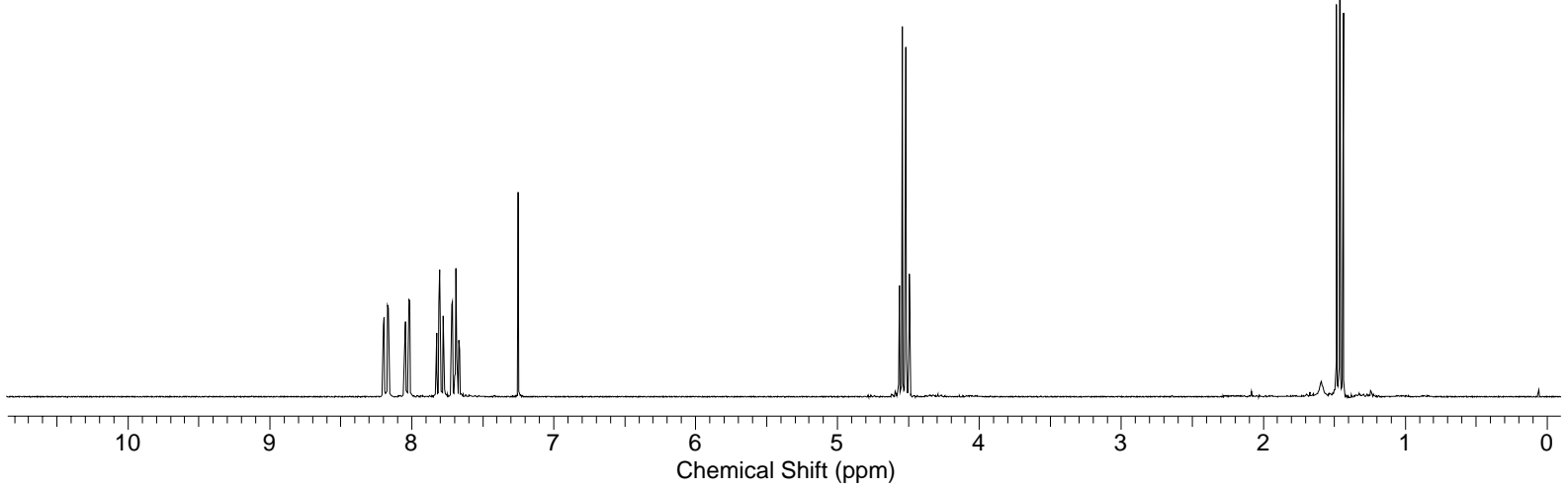<smiles>CCOC(=O)c1c(Br)nc2ccccc2c1Br</smiles>

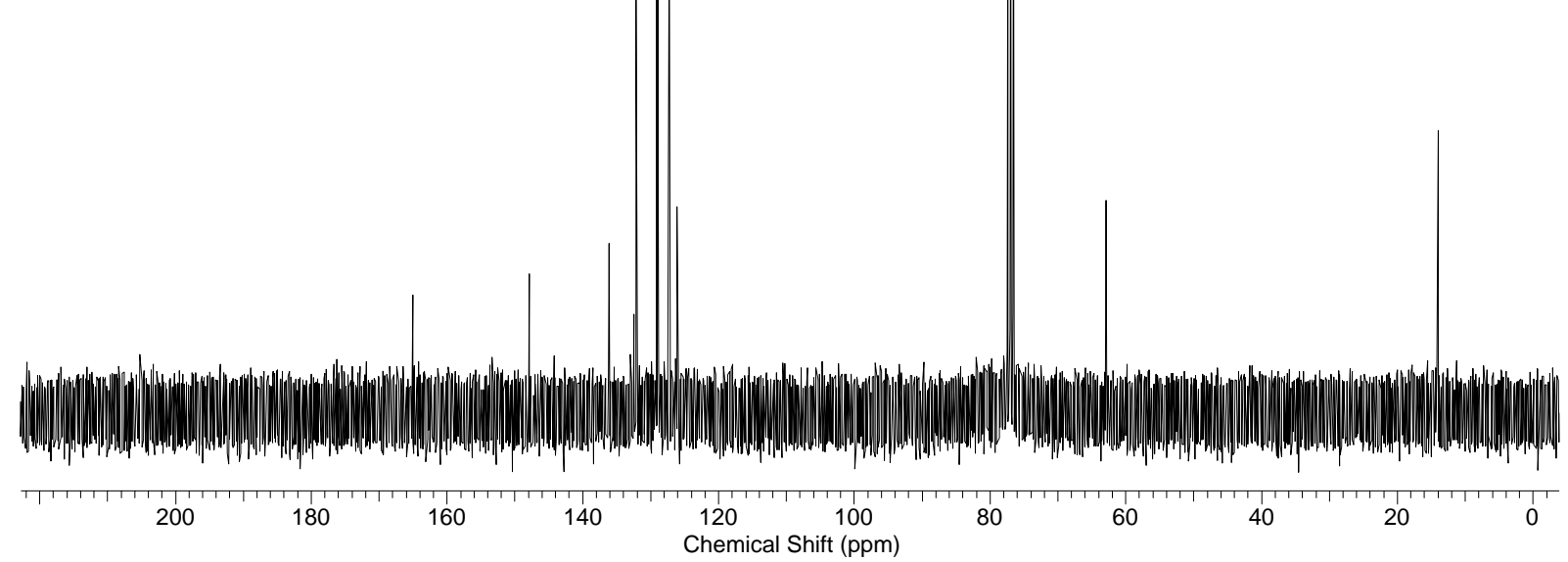


4-bromo-3-methylsulfanylquinoline (11h)<smiles>Cc1cnc2ccccc2c1Br</smiles>

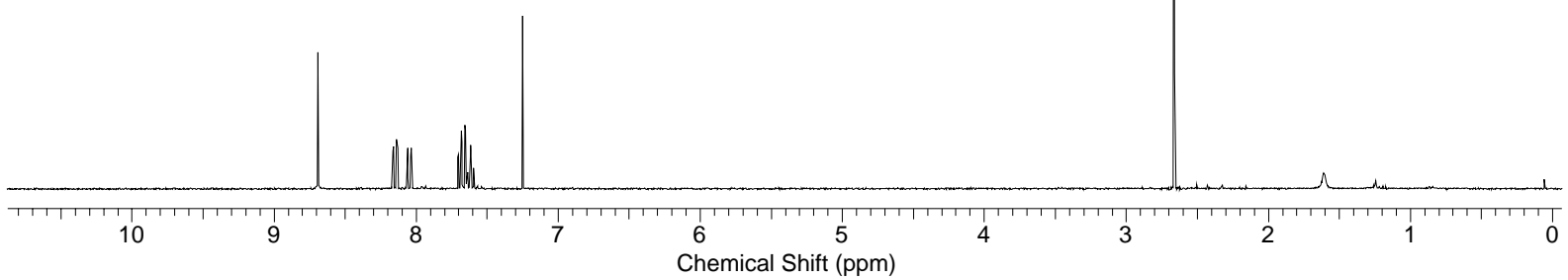<smiles>Cc1cnc2ccccc2c1Br</smiles>

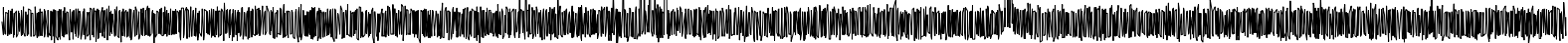

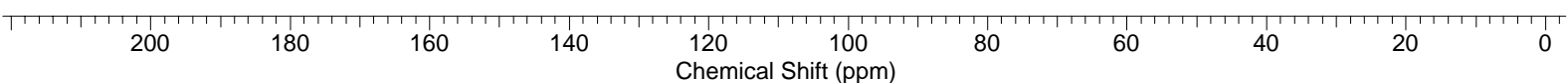


4-(4-bromoquinolin-3-yl)-benzonitrile (11i)

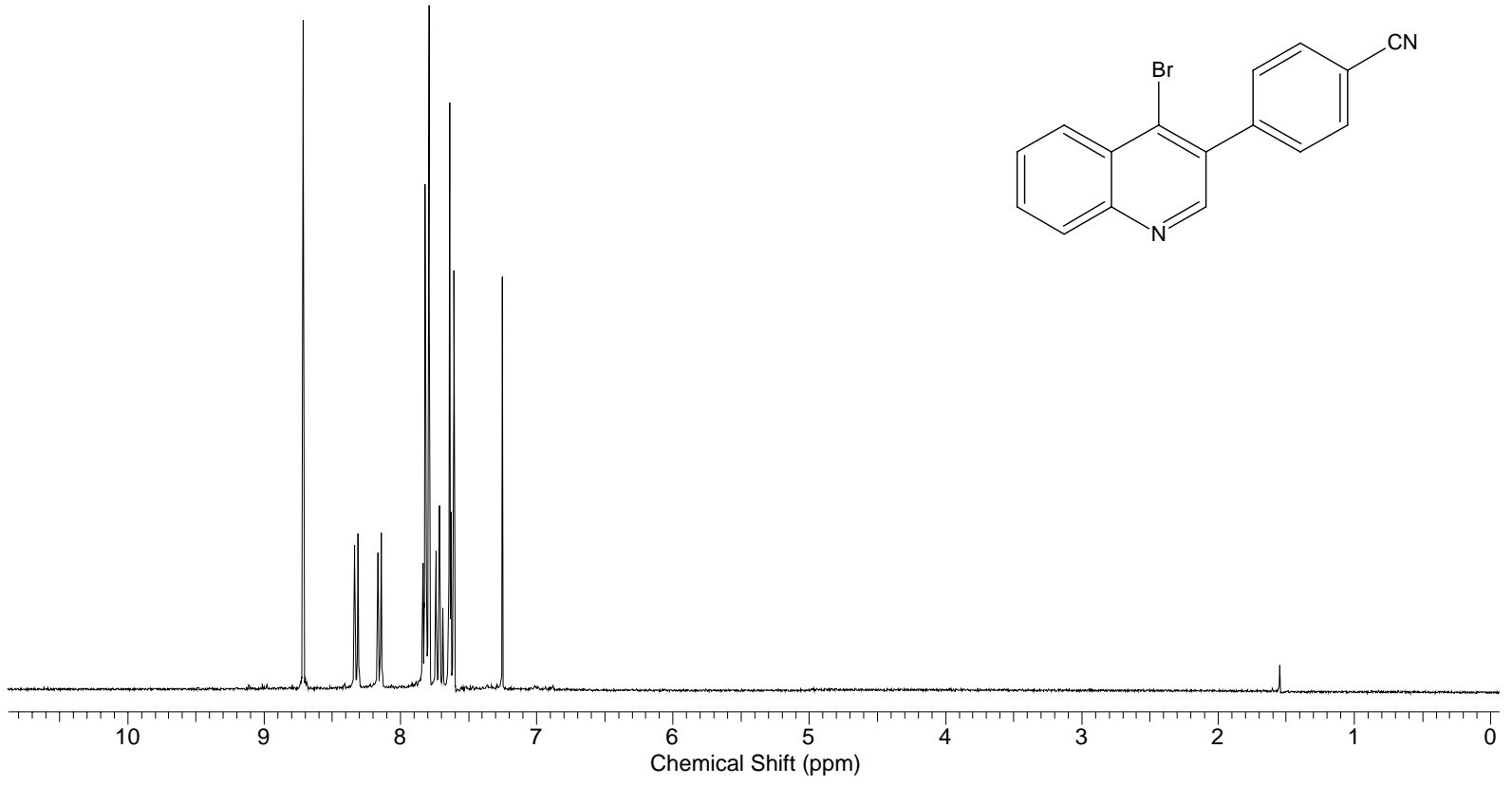

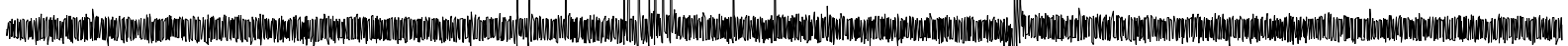

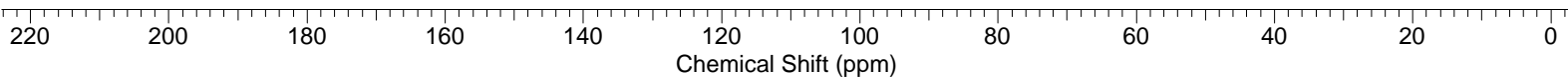


3-benzyl-2,4-dibromoquinoline (11j)
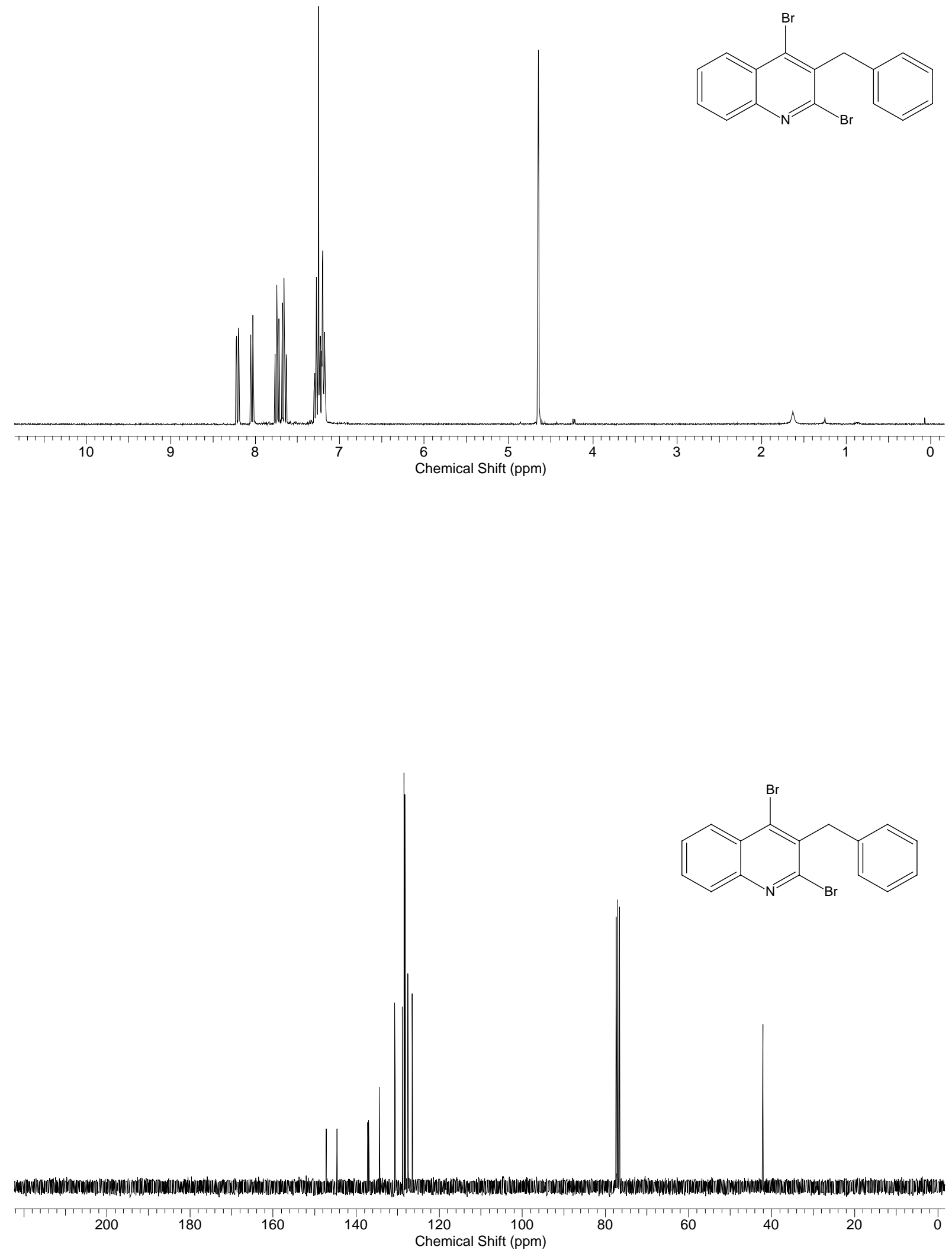
2-bromoquinoline-3-carboxylic acid ethyl ester (11k)<smiles>CCOC(=O)c1cc2ccccc2nc1Br</smiles>

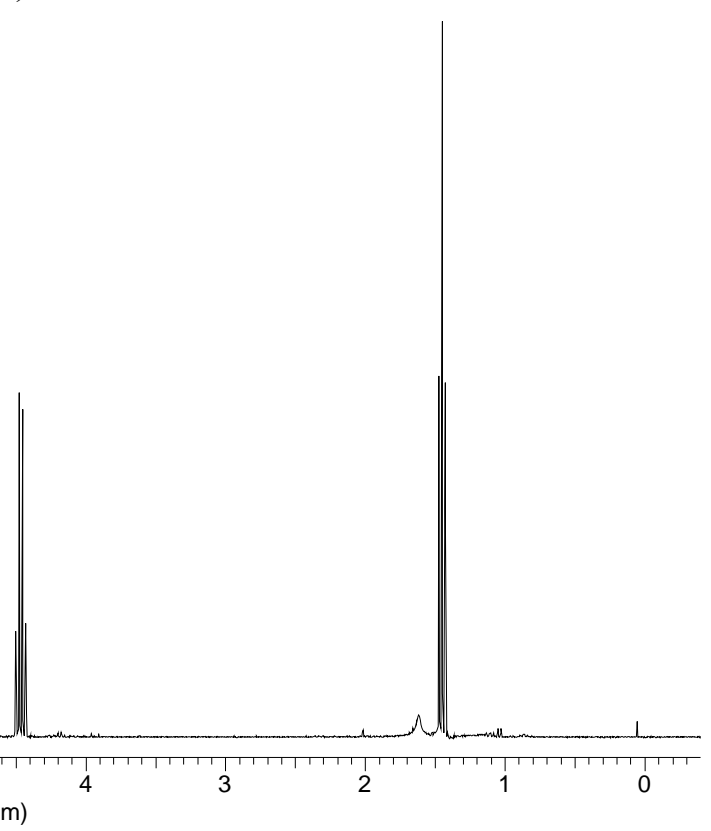<smiles>CCOC(=O)c1cc2ccccc2nc1Br</smiles>

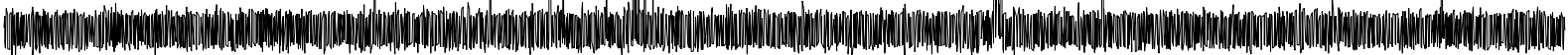

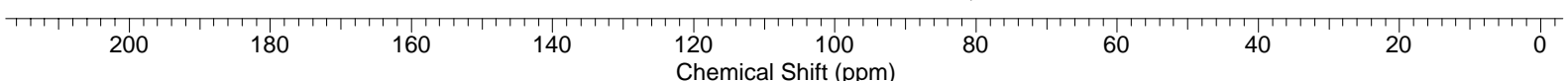


ethyl 2-bromoquinoline-4-carboxylate (11)<smiles>CCOC(=O)c1cc(Br)nc2ccccc12</smiles>

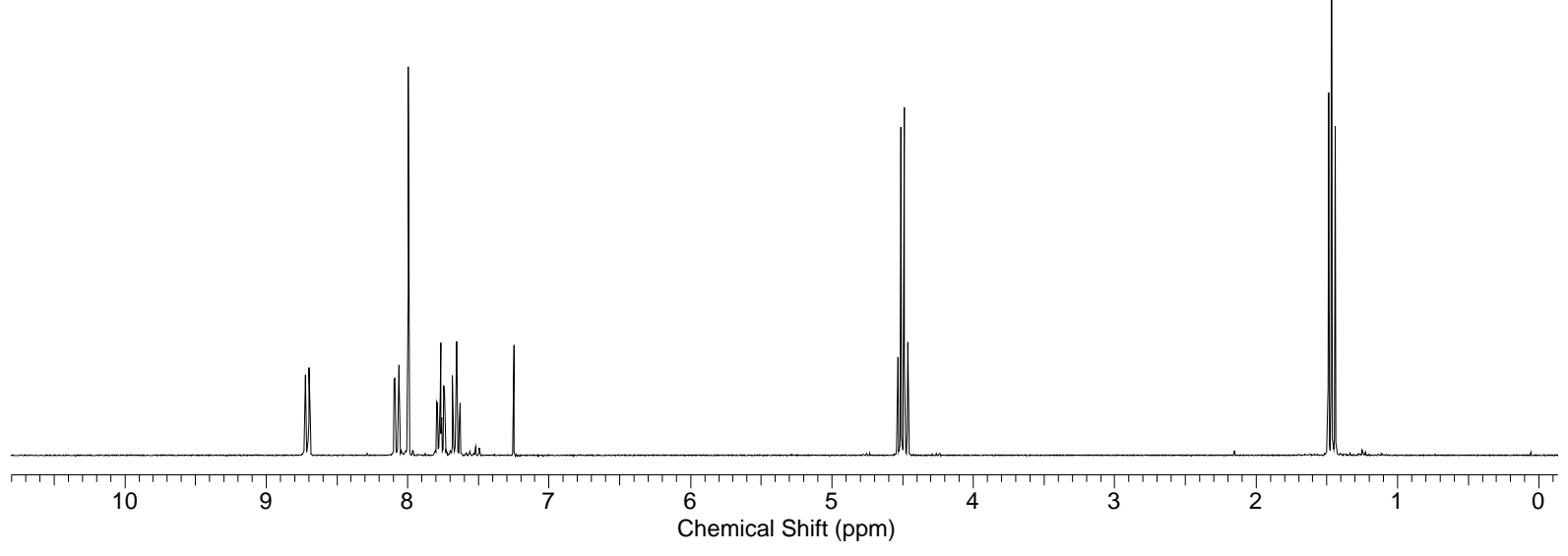<smiles>CCOC(=O)c1cc(Br)nc2ccccc12</smiles>

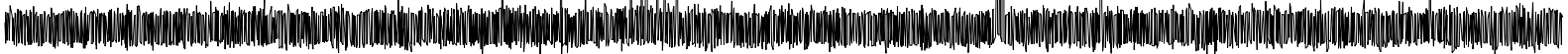

\begin{tabular}{cccccccccccccc}
\hline & 0 & 180 & 160 & 140 & 120 & 100 & 80 & 60 & 40 & 20 & 0
\end{tabular}


3-benzyl-2-bromo-4-methylsulfanyl-quinoline (12)

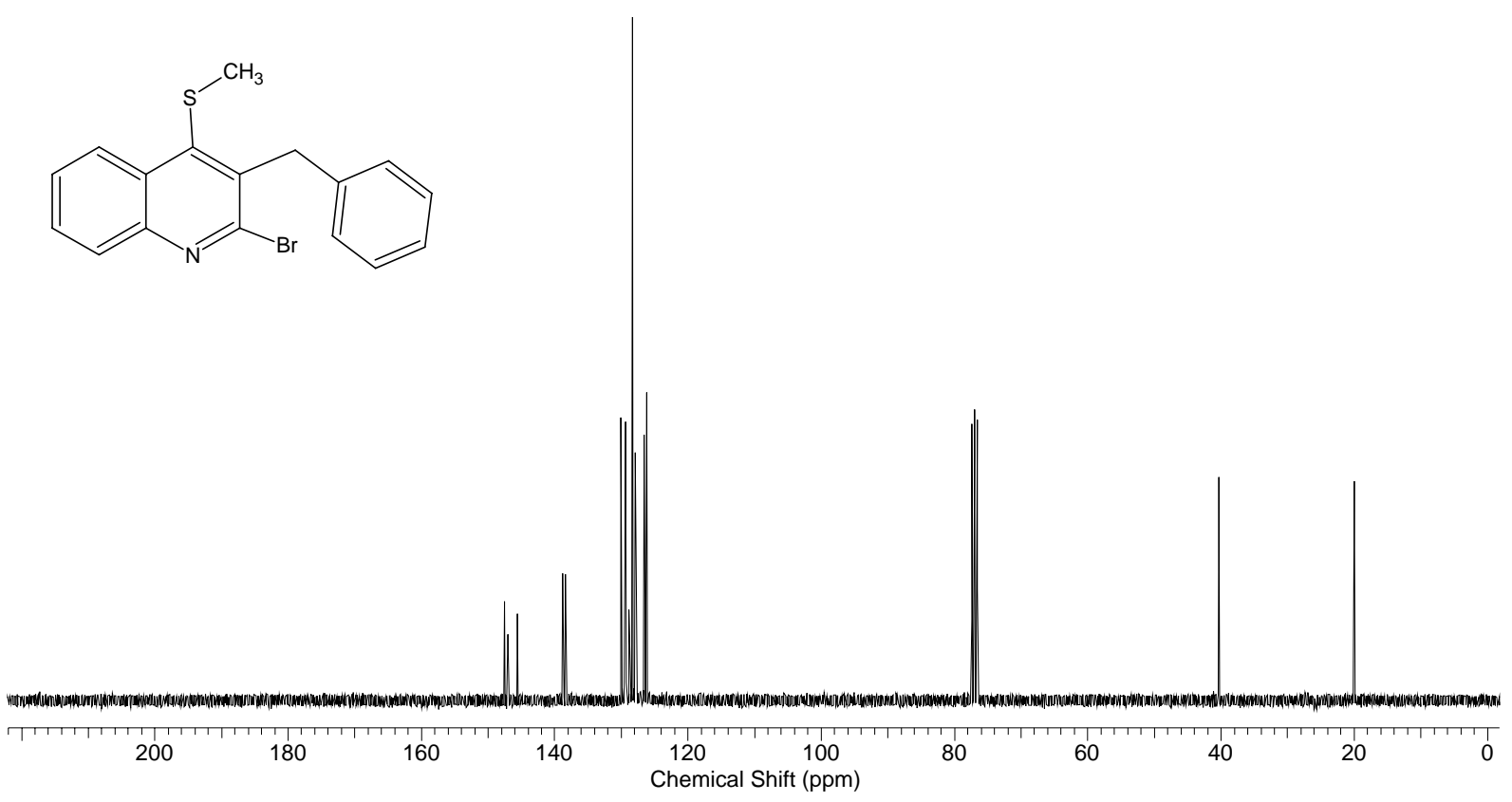<smiles>CSc1c(Cc2ccccc2)c(Br)nc2ccccc12</smiles>

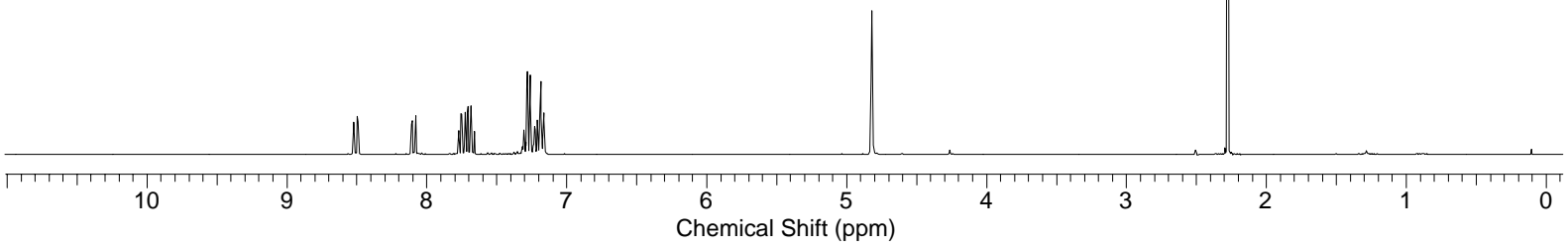


2-(3-benzyl-4-methylsulfanyl-quinolin-2-ylmethyl)-acrylic acid ethyl ester (13)<smiles>C=C(Cc1nc2ccccc2c(SC)c1Cc1ccccc1)C(=O)OCc1ccccc1</smiles>

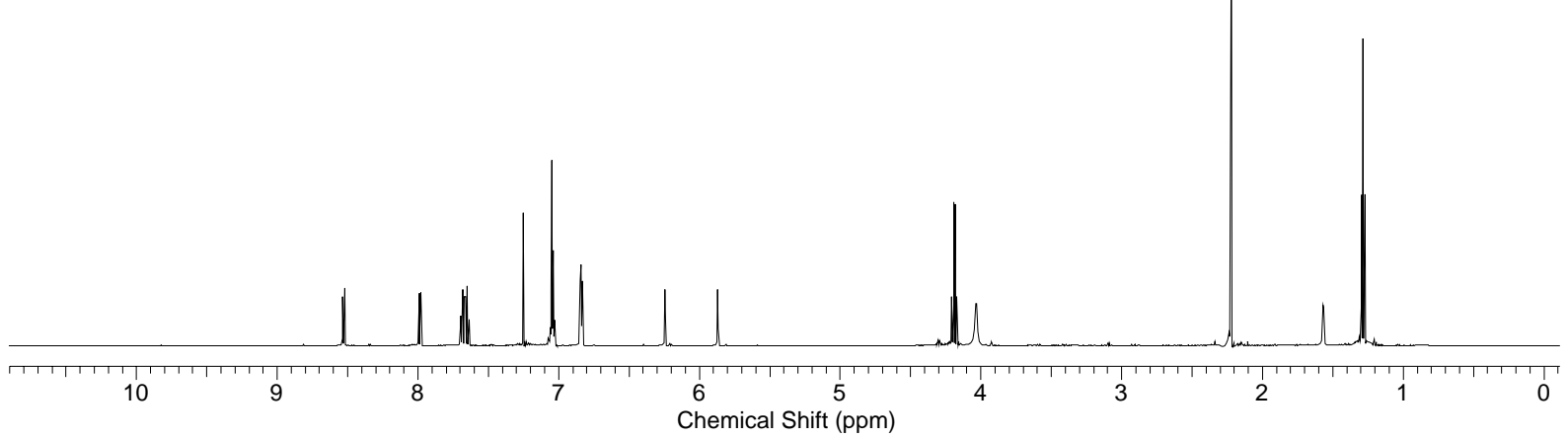<smiles>C=C(Cc1nc2ccccc2c(S)c1Cc1ccccc1)C(=O)OC</smiles>

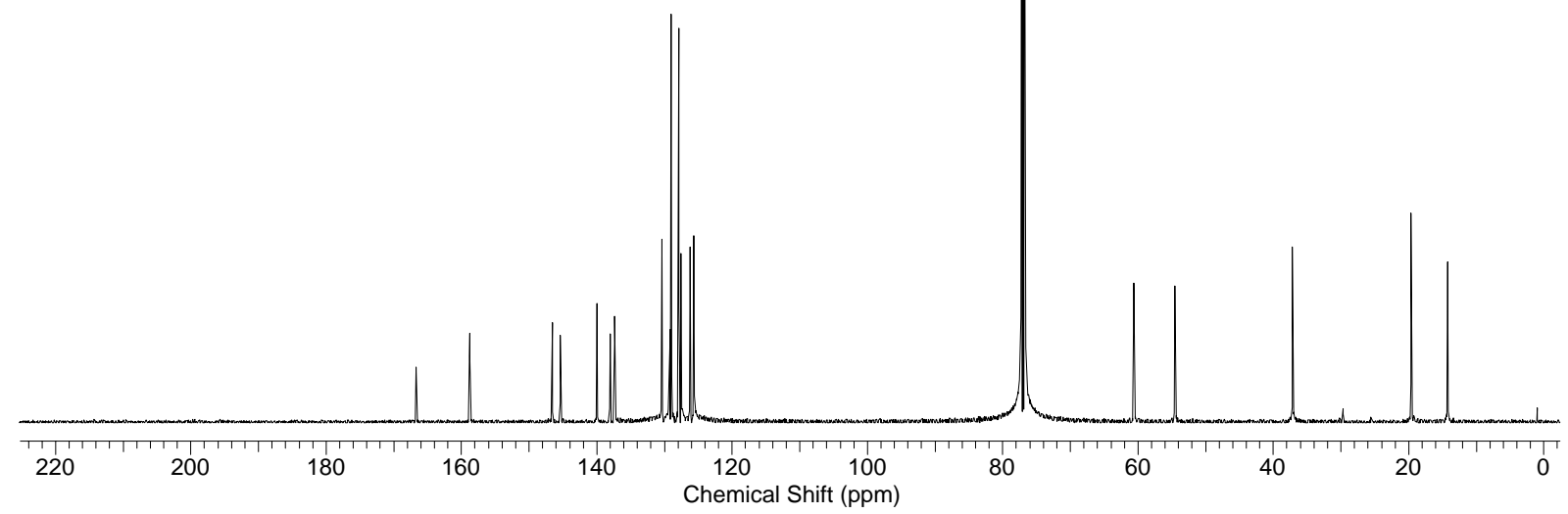


ethyl 2-bromo-4-pivaloylquinoline-3-carboxylate (15)

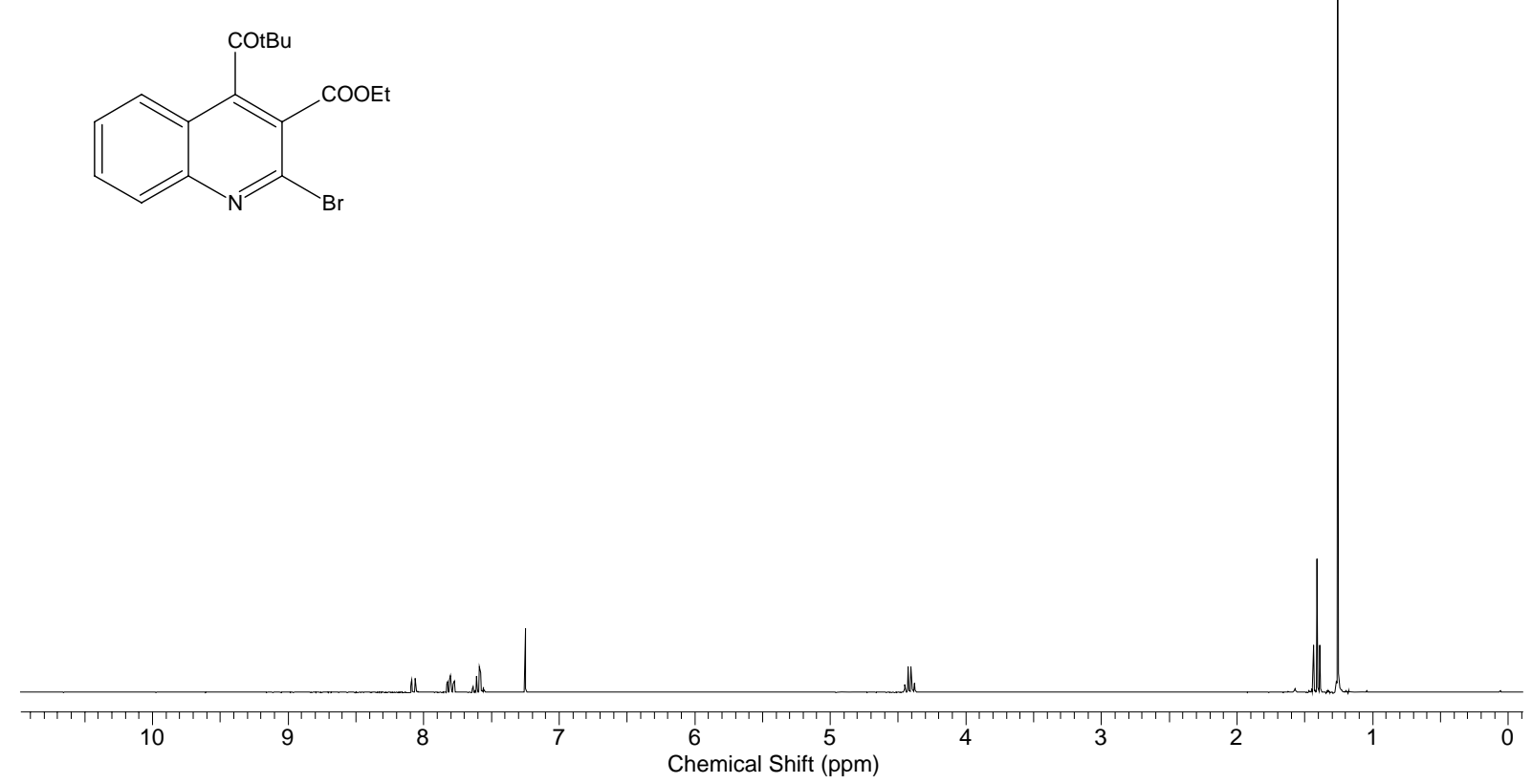<smiles>CCOC(=O)c1c(Br)nc2ccccc2c1C(=O)OCC</smiles>

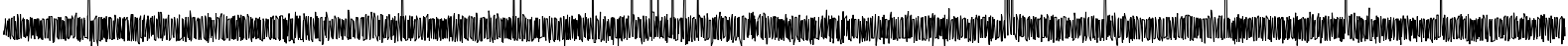

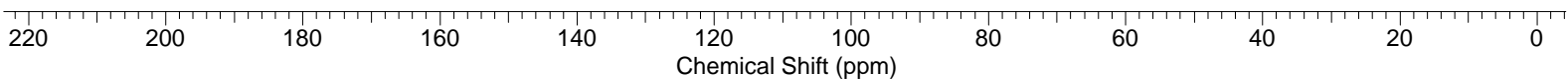


ethyl 2-bromo-3-pivaloylquinoline-4-carboxylate (16)<smiles>CCOC(=O)c1c(Br)nc2ccccc2c1C(=O)OCC</smiles>

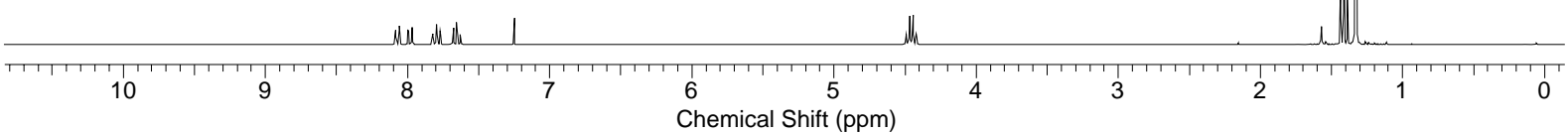<smiles>CCOC(=O)c1c(Br)nc2ccccc2c1C(=O)OCC</smiles>

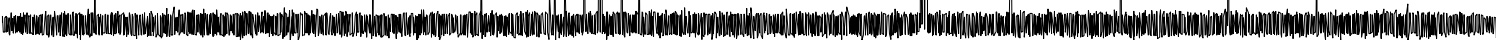

$\begin{array}{llllllllllllll}220 & 200 & 180 & 160 & 140 & 120 & 100 & 80 & 60 & 40 & 20 & 0 & -20 \\ \text { Chemical Shift (ppm) } & & & \end{array}$


2-bromo-3-pivaloyl-8-(4-ethoxycarbonyl-phenyl)-quinoline-4-carboxylic acid ethyl ester (17)<smiles></smiles>

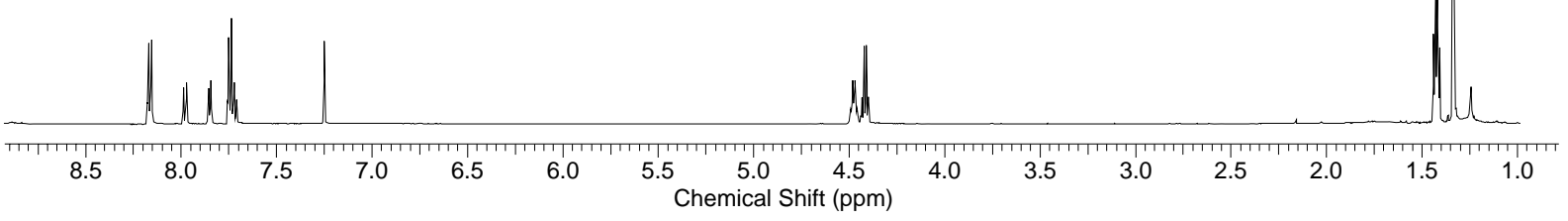<smiles>CCOC(=O)c1ccc(-c2cccc3c(C(=O)OCC)c(C(=O)OCC)c(Br)nc23)cc1</smiles>

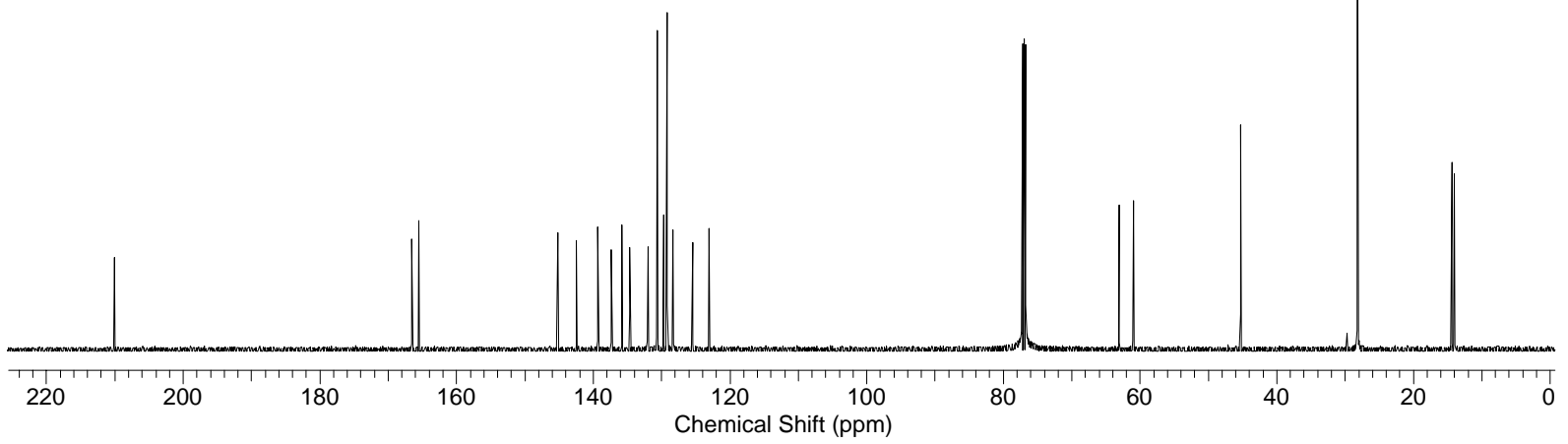


2-ethoxy-4,4,5,5-tetramethyl-[1,3,2]dioxaborolane (ethyl pinacol borate)

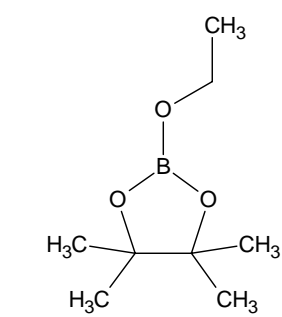
11

10 9

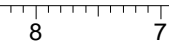
Chemical Shift (ppm) 
2-bromo-3-(4,4,5,5-tetramethyl-[1,3,2]dioxaborolan-2-yl)-quinoline-4-carboxylic acid ethyl ester (18)<smiles>CC(=O)c1c(B2OC(C)(C)C(C)(C)O2)c(Br)nc2ccccc12</smiles>

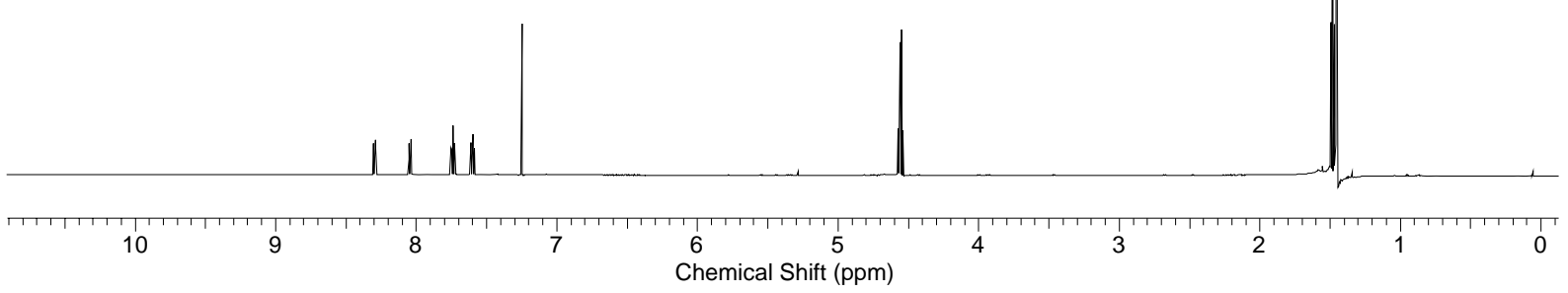<smiles></smiles>

200 180 160 140 
2-phenyl-3-(4,4,5,5-tetramethyl-[1,3,2]dioxaborolan-2-yl)-quinoline-4-carboxylic acid ethyl ester (19)<smiles>CCOC(=O)c1c(B2OC(C)(C)C(C)(C)O2)c(-c2ccccc2)nc2ccccc12</smiles>

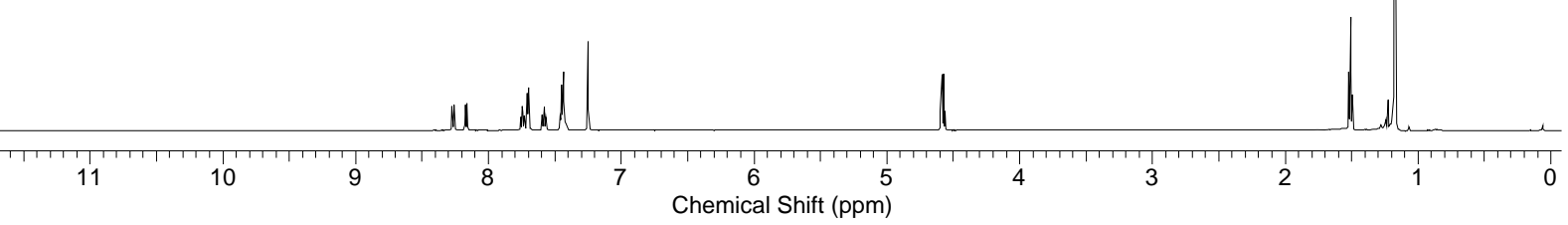<smiles>CCOC(=O)c1c(B2OC(C)(C)C(C)(C)O2)c(-c2ccccc2)nc2ccccc12</smiles>

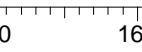
160

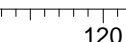


S41

3-Hydroxy-2-phenyl-quinoline-4-carboxylic acid (20)
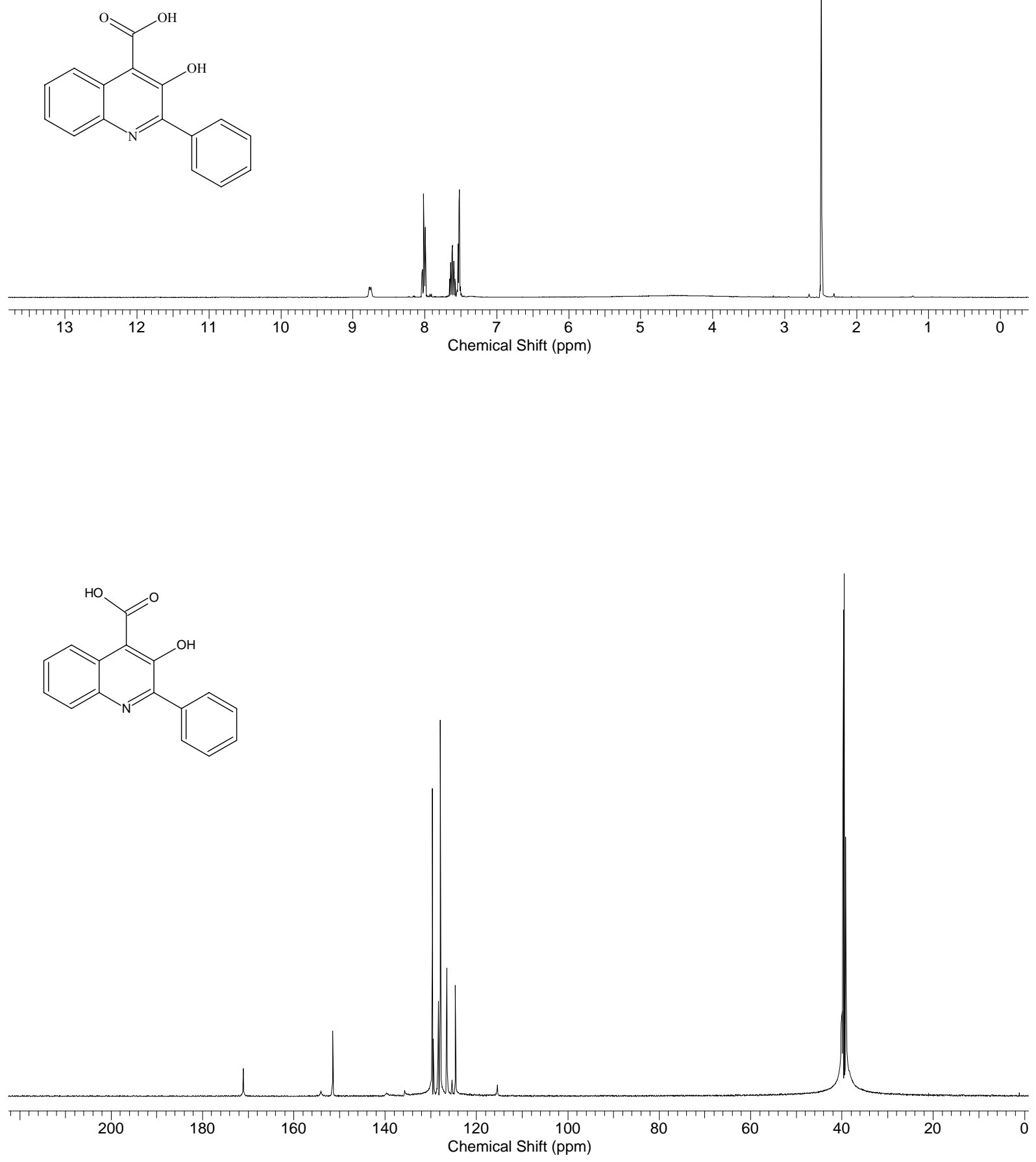


\section{Talnetant (2)}
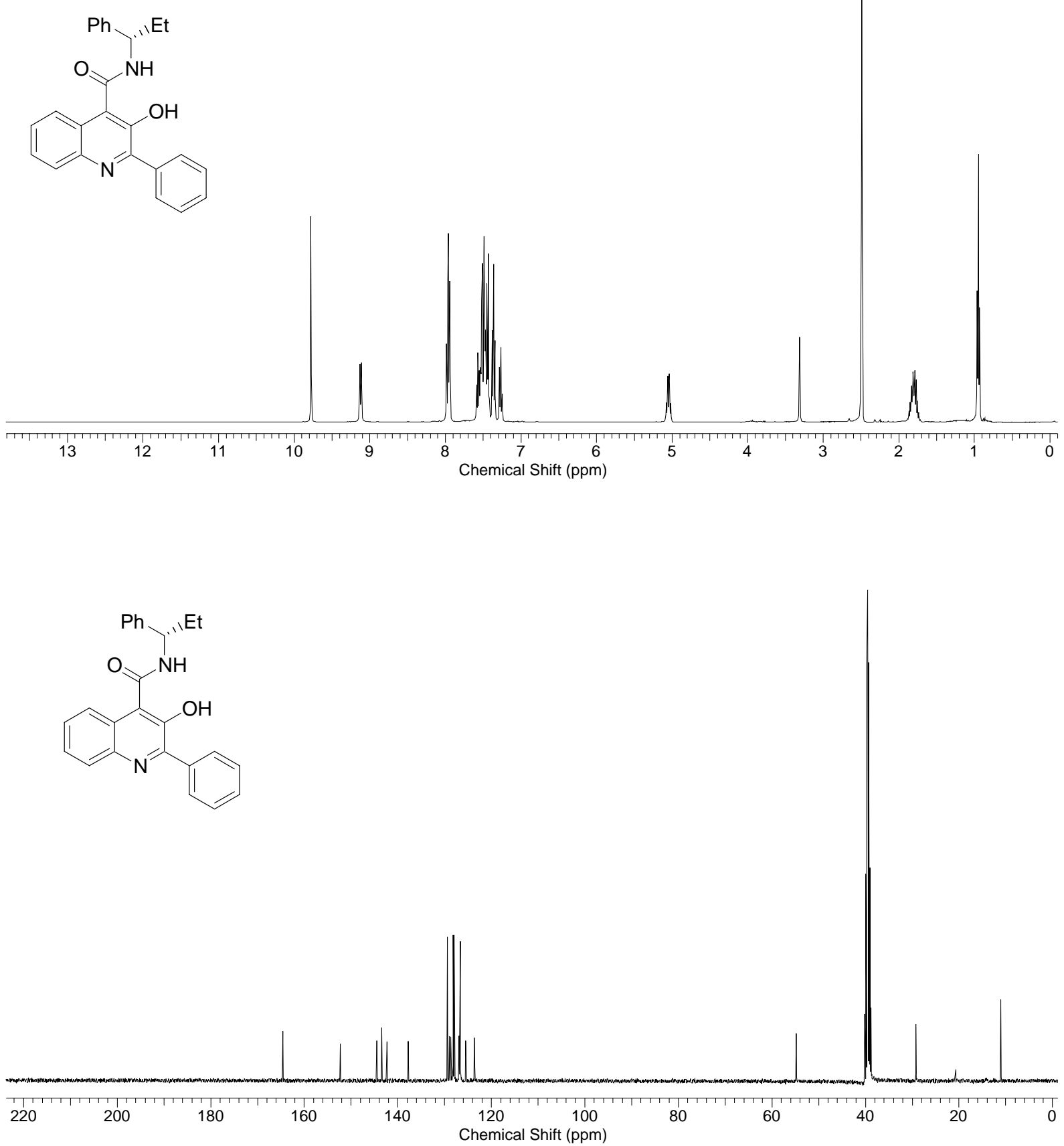